\title{
The distinct roles of anion transporters Slc26a3 (DRA) and Slc26a6 (PAT-1) in fluid and electrolyte absorption in the murine small intestine
}

\author{
Weiliang Xia • Qin Yu • Brigitte Riederer • Anurag Kumar Singh • \\ Regina Engelhardt • Sunil Yeruva • Penghong Song • De-An Tian • \\ Manoocher Soleimani • Ursula Seidler
}

Received: 1 September 2013 /Revised: 9 October 2013 / Accepted: 10 October 2013 /Published online: 14 November 2013

(C) The Author(s) 2013. This article is published with open access at Springerlink.com

\begin{abstract}
The mixing of gastric and pancreatic juice subjects the jejunum to unique ionic conditions with high luminal $\mathrm{CO}_{2}$ tension and $\mathrm{HCO}_{3}{ }^{-}$concentration. We investigated the role of the small intestinal apical anion exchangers PAT-1 (Slc26a6) and DRA (Slc26a3) in basal and $\mathrm{CO}_{2} / \mathrm{HCO}_{3}{ }^{-}$-stimulated jejunal fluid absorption. Single pass perfusion of jejunal segments was performed in anaesthetised wild type (WT) as well as in mice deficient in DRA, PAT- $1, \mathrm{Na}^{+} / \mathrm{H}^{+}$exchanger 3 (NHE3) or NHE2, and in carbonic anhydrase II (CAII). Unbuffered saline ( $\mathrm{pH}$ 7.4) perfusion of WT jejunum resulted
\end{abstract}

Weiliang Xia and Qin Yu contributed equally to this work.

Electronic supplementary material The online version of this article (doi:10.1007/s00424-013-1381-2) contains supplementary material, which is available to authorized users.

W. Xia $\cdot$ Q. Yu $\cdot$ B. Riederer · A. K. Singh $\cdot$ R. Engelhardt $\cdot$ $\mathrm{S}$. Yeruva $\cdot \mathrm{U}$. Seidler

Department of Gastroenterology, Hannover Medical School, Hannover, Germany

Q. Yu - D.-A. Tian

Department of Gastroenterology, Tongji Hospital, Huazhong

University of Science and Technology, Wuhan, China

P. Song

Key Laboratory of Combined Multiorgan Transplantation, The First Affiliated Hospital, School of Medicine, Zhejiang University,

Hangzhou 310003, China

M. Soleimani

Center on Genetics of Transport and Epithelial Biology,

University of Cincinnati, Cincinnati, OH, USA

U. Seidler $(\square)$

Department of Gastroenterology, Hepatology and Endocrinology,

Hannover Medical School, Carl-Neuberg-Straße 1,

0625 Hannover, Germany

e-mail: seidler.ursula@mh-hannover.de in fluid absorption and acidification of the effluent. DRAdeficient jejunum absorbed less fluid than WT, and acidified the effluent more strongly, consistent with its action as $\mathrm{a} \mathrm{Cl}^{-} /$ $\mathrm{HCO}_{3}{ }^{-}$exchanger. PAT-1-deficient jejunum also absorbed less fluid but resulted in less effluent acidification. Switching the luminal solution to a $5 \% \mathrm{CO}_{2} / \mathrm{HCO}_{3}{ }^{-}$buffered solution $\left(\mathrm{pH}\right.$ 7.4), resulted in a decrease in jejunal enterocyte $\mathrm{pH}_{\mathrm{i}}$ in all genotypes, an increase in luminal surface $\mathrm{pH}$ and a strong increase in fluid absorption in a PAT-1- and NHE3- but not DRA-, CAII, or NHE2-dependent fashion. Even in the absence of luminal $\mathrm{Cl}^{-}$, luminal $\mathrm{CO}_{2} / \mathrm{HCO}_{3}{ }^{-}$augmented fluid absorption in WT, CAII, NHE2- or DRA-deficient, but not in PAT-1- or NHE3-deficient mice, indicating the likelihood that PAT-1 serves to import $\mathrm{HCO}_{3}{ }^{-}$and $\mathrm{NHE} 3$ serves to import $\mathrm{Na}^{+}$ under these circumstances. The results suggest that PAT-1 plays an important role in jejunal $\mathrm{Na}^{+} \mathrm{HCO}_{3}^{-}$reabsorption, while DRA absorbs $\mathrm{Cl}^{-}$and exports $\mathrm{HCO}_{3}^{-}$in a partly CAIIdependent fashion. Both PAT-1 and DRA significantly contribute to intestinal fluid absorption and enterocyte acid/ base balance but are activated by different ion gradients.

Keywords Bicarbonate $\cdot$ Intestine $\cdot$ Acid/base balance . Intestinal electrolyte absorption

$\begin{array}{ll}\text { Abbreviations } \\ \text { ACC } & \text { Acetylcysteine } \\ \text { CA2 } & \text { Carbonic anhydrase 2 } \\ \text { DRA } & \text { Downregulated in adenoma } \\ \text { KO } & \text { Knockout } \\ \text { NHE } & \mathrm{Na}^{+} / \mathrm{H}^{+} \text {exchanger } \\ \text { NMDG } & \mathrm{N} \text {-Methyl-D-glucamine } \\ \text { PAT-1 } & \text { Putative anion transporter 1 } \\ \text { WT } & \text { Wild type } \\ \text { CAII } & \text { Carbonic anhydrase II }\end{array}$




\section{Introduction}

The $\mathrm{pH}$ profile of the small intestine has been measured in laboratory animals and humans by microelectrodes attached to the mucosa or by capsule radiotelemetry in the interdigestive as well as the postprandial state $[29,33]$. The steepest $\mathrm{pH}$ gradient was found in the first $10 \mathrm{~cm}$ of the duodenum, where the $\mathrm{pH}$ increased from 2 to 5 in the interdigestive state and from 1.7 to 4.3 in the postprandial state [33]. Another $\mathrm{pH}$ increase occurs after the duodeno-jejunal junction, where intraluminal $\mathrm{pH}$ may become alkaline [29]. In addition, luminal $\mathrm{CO}_{2}$ tension as well as $\mathrm{HCO}_{3}{ }^{-}$concentration is particularly high in the distal duodenum and proximal jejunum, where the acidic gastric juice mixes with the alkaline pancreatic juice. Thus the proximal jejunum is regularly exposed to a very unique luminal ionic composition, with high $\mathrm{CO}_{2}$ tension, high $\mathrm{HCO}_{3}{ }^{-}$concentration, and relatively low $\mathrm{Cl}^{-}$concentration (because pancreatic juice is low in $\mathrm{Cl}^{-}$).

Early in vivo studies in laboratory animals as well as in humans have observed marked differences in water and salt absorption between the jejunum and ileum, with the major part of jejunal absorption during saline perfusion being presumably due to passive diffusion $[11,12,37]$. On the other hand, bicarbonate was actively absorbed in the jejunum and caused stimulation of fluid absorption [47, 48]. This process was largely $\mathrm{Na}^{+}$-dependent and generated an increase of luminal $\mathrm{CO}_{2}$, suggesting it to be mediated by luminal $\mathrm{Na}^{+} /$ $\mathrm{H}^{+}$exchange [47]. $\mathrm{A} \mathrm{Na}^{+}$-independent component of human jejunal $\mathrm{HCO}_{3}{ }^{-}$absorption was described by Hubel [18] and in rat jejunum by Podesta and Mettrick [35]. No studies exist which have systematically studied the molecular candidates for jejunal bicarbonate-stimulated fluid absorption.

Current dogma envisions small intestinal fluid absorption to occur as an electroneutral process via the coordinated action of $\mathrm{Na}^{+} / \mathrm{H}^{+}$and $\mathrm{Cl}^{-} / \mathrm{HCO}_{3}^{-}$exchangers [20]. Isolated brush border membranes from the small intestine, mostly the ileum, of a variety of species displayed proton-driven $\mathrm{Na}^{+}$uptake as well as $\mathrm{HCO}_{3}{ }^{-}$-driven $\mathrm{Cl}^{-}$uptake [21-24, 32]. Expression studies have identified several potential molecular candidates for these apical $\mathrm{Na}^{+} / \mathrm{H}^{+}$and $\mathrm{Cl}^{-} / \mathrm{HCO}_{3}{ }^{-}$exchangers. In murine jejunum, the $\mathrm{Na}^{+} / \mathrm{H}^{+}$exchanger (NHE) isoforms NHE3 and NHE2 are expressed in a villus-predominant apical localization [5, 17]. The Slc26 anion transporter family members Slc26a6 (putative anion transporter-1 [PAT-1]) and Slc26a3 (downregulated in adenoma [DRA]) are co-localized with these NHEs in jejunal villi. However, the expression levels of DRA and PAT-1 display inverse gradients along the gastrointestinal (GI) tract of rodents and man, with PAT-1 showing a particularly strong expression in the upper small intestine, and very low expression in the colon [51].

Both DRA [10, 25, 26, 30] and PAT-1 appeared to function as $\mathrm{Cl}^{-} / \mathrm{HCO}_{3}{ }^{-}$exchangers in expression systems $[9,14,39]$. While this suggested that both DRA and PAT-1 may work in parallel to absorb $\mathrm{Cl}^{-}$[20], this concept was challenged by a number of observations: First, controversial results were obtained regarding the stoichiometry of $\mathrm{Cl}^{-}$and $\mathrm{HCO}_{3}{ }^{-}$ coupling for these exchangers, with some data indicating the electroneutrality of the exchange $[2,9,25,26]$, while others suggesting a 2:1 coupling of $\mathrm{Cl}^{-}$and $\mathrm{HCO}_{3}{ }^{-}$for DRA and the opposite for PAT-1 [39]. Second, the intracellular $\mathrm{pH}\left(\mathrm{pH}_{\mathrm{i}}\right)$ of DRA-deficient duodenal villous enterocytes was found to be higher than wild type (WT), while that of PAT-1-deficient enterocytes was lower than WT enterocytes in isolated sheets of duodenal mucosa [50], suggesting that during the conditions of those experiments, the two transporters may transport $\mathrm{HCO}_{3}{ }^{-}$in opposite directions. In addition, the role of PAT-1 in $\mathrm{Cl}^{-}$absorption was relatively small in isolated murine jejunal mucosa $[38,50]$. PAT- 1 also has been linked to oxalate secretion into the intestinal lumen [13], but this function fails to explain the high expression of PAT-1 in the upper small intestine, in particular since DRA has been shown to function as an oxalate absorber in the lower intestine [15]. Taken together, these findings indicated that the physiological significance for the very high expression of PAT-1 in the upper small intestine has yet to be clarified.

Carbonic anhydrase II (CAII) binds to PAT-1 in expression systems, and the mutation of the CAII binding site of PAT-1 strongly decreased PAT-1 transport activity [3]. In isolated small intestinal mucosa, the measurement of $\mathrm{Cl}^{-} / \mathrm{HCO}_{3}{ }^{-}$ exchange in the presence of the dipeptide Gly-Sar (which is transported coupled to protons via PEPT1 in small intestine) revealed an increased rate of $\mathrm{Cl}^{-}{ }_{\text {(OUT) }} / \mathrm{HCO}_{3}{ }^{-}$(IN) exchange that was both PAT-1 dependent and CAII dependent [41]. To better understand the role of CAII in small intestinal transport physiology, we therefore also included CAII KO mice in the analysis.

It is known that the small intestine not only absorbs $\mathrm{NaCl}$ and fluid, but also reabsorbs large quantities of $\mathrm{HCO}_{3}{ }^{-}$[47]. The loss of this function, i.e., in patients with an enterostomy, can precipitate severe dysfunctions in systemic acid/base balance that cannot be compensated for by the kidneys and may result in renal stone formation, kidney failure, and osteopenia [52]. The molecular mechanisms of small intestinal $\mathrm{HCO}_{3}{ }^{-}$reabsorption have not been clarified in detail, and this study was designed to close this gap. Utilizing knockout (KO) mice for NHE2 and NHE3, as well as for PAT-1, DRA and CAII, jejunal segments of artificially ventilated mice with systemically controlled acid/base balance were perfused with prewarmed solutions of known controlled compositions. Thereafter, the changes in volume and $\mathrm{pH}$ of the outflowing solutions were determined. Fluorometric measurements of microdissected jejunal villi loaded with the $\mathrm{pH}$ indicator BCECF were used for in vitro $\mathrm{pH}_{\mathrm{i}}$ measurements, and twophoton microscopy of exteriorised, vascularly perfused jejunal mucosa in anaesthetised mice was performed for in vivo $\mathrm{pH}_{\mathrm{i}}$ assessment during the conditions of these experiments. 


\section{Materials and methods}

Animals and ethics

All experiments involving animals were approved by the Hannover Medical School Committee on investigations involving animals and an independent committee assembled by the local authorities. Experiments were performed with WT and gene deficient KO mouse models of Slc26a3 (DRA), Slc26a6 (PAT-1), Slc9a3 (NHE3), Slc9a2 (NHE2) and CAII. The origin of these mice is indicated elsewhere [38, 43, 44]. Mice were bred at the animal care facility of Hannover Medical School under standard temperature and light conditions and were allowed free access to food and water. The DRA, PAT-1, NHE3 and CAII WT and KO mice were congenic on C57BL/ $6 \mathrm{~N}$ background, whereas the NHE2 WT and KO mice were congenic on NMRI background. The DRA mice KO were fed a special diet (Altromin, Lage, Germany, Cat. no. C0197) and drinking water containing $(\mathrm{KCl} 10 \mathrm{mM}, \mathrm{NaCl} 7.5 \mathrm{mM}$, sodium citrate $5 \mathrm{mM}$ and sucrose $35 \mathrm{mM}$ ), which enables survival beyond weaning. The NHE3 KO mice were also fed a special diet (Altromin, Cat. no. 1057). The special diet was introduced to the respective WT at least 2 weeks prior to the experiments, or, if feasible, the special diet was removed prior to the experiments, and WT and KO mice were fed the same diet. Care was taken to ensure an approximately equal number of male and female pairs of WT and KO mice in each group of experiments. All experiments were performed in mice aged between 10-16 weeks. We tried to use littermates, if that was not possible we used WT mice of similar age/gender, from the same grandparental lineage. Genotyping was performed from tail or ear tissues as described, and the primer sequences are given in the Supplementary files.

\section{Quantitative PCR protocol}

RNA isolation as well as the PCR followed published protocols [6], with further details given in the Supplementary files.

\section{Histology and immunostaining}

Tissue processing for cryofixation and NHE3 immunostaining, as well as the quantitative analysis of the NHE3 localization along the micovillar length, was performed exactly as previously described, and care was taken to image the WT and KO sections at identical settings of the confocal microscope [28].

In vivo fluid absorptive rate and effluent $\mathrm{pH}$ measurements

\section{Surgical procedures}

The mice were anaesthetised by isoflurane (Forene, Abbott Germany, Wiesbaden, Germany) via tracheal intubation connecting to the mechanical ventilator (MiniVent Type 845; Hugo Sachs Electronik, March-Hugstetten, Germany). The surgical procedure was performed exactly as described for the duodenum $[45,46]$,with the following modification: after the middle incision in the abdomen, about a 3-cm length of proximal jejunum with an intact blood supply was selected for the experiments. The jejunum was perfused (Gilson minipulse evolution, Villiers, France) at a rate of $30 \mathrm{ml} \mathrm{h}^{-1}$ and the effluent collected for further use. Blood was sampled from the carotid artery catheter for blood gas analysis, as described [45]. The blood gas values at the end of the experiment are given in Table S2 for the PAT-1 WT and KO mice, and the NHE3 WT and KO mice, and has already been published for the DRA KO mice [44] and the CAII KO mice $[27,46]$.

\section{Measurement of jejunal fluid absorptive rates}

Measurement of fluid absorption was performed as described previously $[44,45,53]$, with modifications. The perfusion rate was $30 \mathrm{ml} \mathrm{h}^{-1}$ in a single pass manner to ensure optimal expansion of the jejunal lumen. Water loss by evaporation due to gassing at $37^{\circ} \mathrm{C}$ was measured simultaneously in another aliquot which was equally treated, but not perfused through the mouse intestine, and accounted for in the calculation. The fluid absorption rates $\left(\mu \mathrm{cm}^{-1} \mathrm{~h}^{-1}\right)$ were calculated according to the absorptive fluid loss (taking density of fluid roughly at about $1 \mathrm{mg} \mathrm{ml}^{-1}$ ), jejunal length $(\mathrm{cm})$ and perfusion time $(\mathrm{h})$. The composition of the perfusate solutions is given in Table $\mathrm{S} 1$.

\section{Measurement of pH values of effluent solutions}

Before perfusion, the unbuffered perfusate solutions were adjusted to the $\mathrm{pH}$ of 7.4 in a $37^{\circ} \mathrm{C}$ water bath by using $\mathrm{pH}$ stat microtitration (Radiometer, Copenhagen). After $20 \mathrm{~min}$ perfusion, the $\mathrm{pH}$ values of effluent solutions were measured. The $\mathrm{pH}$ values of the residual perfusate solutions on the inflow side were also measured to assess $\mathrm{pH}$ drifts. The difference between the $\mathrm{pH}$ of an effluent solution and its corresponding residual perfusate solution was used to evaluate the acidification or alkalinisation of effluent.

Fluorometric $\mathrm{pH}_{\mathrm{i}}$ measurements of jejunocytes in intact jejunal villi

Preparation of isolated jejunal villi for fluorometry and $\mathrm{pH}$ measurements were performed exactly as previously described [7], except for the use of different solutions and protocols. The buffer solutions are: For the experiments described in Figs. 6, 7, 8, S1, S2, S3 and Table S3, the buffer solutions are: Buffer A (solution composition in mM: 130 $\mathrm{NaCl}, 10$ Hepes, 5 Tris, $2.25 \mathrm{KH}_{2} \mathrm{PO}_{4}, 1.5 \mathrm{~K}_{2} \mathrm{HPO}_{4}, 1.2$ 
$\mathrm{MgSO}_{4}, 1.2 \mathrm{Ca}$ gluconate, $\mathrm{pH} 7.4$ gassed with oxygen) or buffer A containing $10 \mathrm{mM}$ glucose (replacing $10 \mathrm{mM} \mathrm{NaCl}$ ) for $20 \mathrm{~min}$ for a stable baseline reading, then switch and buffer B [solution composition in mM: $108 \mathrm{NaCl}, 22 \mathrm{NaHCO}_{3}, 10$ Hepes, 5 Tris, $2.25 \mathrm{KH}_{2} \mathrm{PO}_{4}, 1.5 \mathrm{~K}_{2} \mathrm{HPO}_{4}, 1.2 \mathrm{MgSO}_{4}, 1.2 \mathrm{Ca}$ gluconate, $\mathrm{pH} 7.4$ gassed with carbogen $\left.\left(5 \% \mathrm{CO}_{2}-95 \% \mathrm{O}_{2}\right)\right]$ or buffer B containing $10 \mathrm{mM}$ glucose (replacing $10 \mathrm{mM} \mathrm{NaCl}$ ). Steady-state $\mathrm{pH}_{\mathrm{i}}$ (shown in Figs. S1, 7 and 8, and Table S3) was determined as described previously [7]. For experiments shown in Fig. S2, the microdissected villi were perfused with prewarmed oxygenated buffer A for $20 \mathrm{~min}$ for a stable baseline reading, then the perfusate was switched to buffer $B$ and further readings were taken for $10 \mathrm{~min}$. Steady-state $\mathrm{pH}$ was determined as previously described [7]. Approximately two to three villi were measured per experiment, and the results of these measurements averaged for each mouse; $\mathrm{n}$ is the number of mice.

For the assessment of acid-activated NHE3 activity in intact microdissected jejunal villi, the technique was used as described by Chen et al. [8] with minor modifications. Villous enterocytes were acidified to $\mathrm{pH}_{\mathrm{i}} \sim 6.4$, and $\mathrm{Na}^{+} / \mathrm{H}^{+}$exchange activity was assessed as the initial rate of $\mathrm{pH}$ recovery after the $\mathrm{Na}^{+}$-free buffer was switched to $\mathrm{Na}^{+}$-containing buffer $\mathrm{C}(25$ $\mathrm{NaCl}, 95$ TMACl, 10 Hepes, 5 Tris, $2.25 \mathrm{KH}_{2} \mathrm{PO}_{4}, 1.5$ $\mathrm{K}_{2} \mathrm{HPO}_{4}, 1.2 \mathrm{MgSO}_{4}, 1.2 \mathrm{Ca}$ gluconate, 10 glucose, $\mathrm{pH} 7.4$ gassed with oxygen); $50 \mu \mathrm{M}$ HOE642 was present both in $\mathrm{Na}^{+}$-free buffer and $\mathrm{Na}^{+}$-containing buffer $\mathrm{C}$ in the first recovery pulse to eliminate the contribution of NHE1 and NHE2; both $50 \mu \mathrm{M}$ HOE642 and $10 \mu \mathrm{M}$ S1611 (NHE3 specific inhibitor) were present during the recovery from a second ammonium prepulse to inhibit also NHE3 activity. The rates of $\mathrm{pH}_{\mathrm{i}}$ change measured in the experiments were converted to proton flux $\left(\mathrm{H}_{\mathrm{H}}^{+}\right)$by using the equation $J_{\mathrm{H}}{ }^{+}=\Delta \mathrm{pH} / \Delta t \times \beta_{i}$, where $t$ equals time. NHE3 activity was calculated as the proton flux in the first recovery pulse minus the proton flux in the second recovery pulse.

Two-photon confocal microscopy in vivo measurements

\section{$\mathrm{pH}_{i}$ measurement in the jejunuocytes}

The jejunum of the anaesthetised mouse was exteriorised with intact blood supply, opened near the mesenteric axis and mounted on a custom-made perfusion chamber as previously described $[4,46]$. The exposed jejunal segment was incubated with $1 \mathrm{ml}$ of $6 \mathrm{mM}$ acetylcysteine (ACC) solution in saline for 15 min after surgery, and then followed by forced washing with the saline using a 10-ml syringe to remove accumulated mucus. The loading of the jejunocytes of the villi was achieved by incubation with $20 \mu \mathrm{M}$ SNARF-1 AM for $10 \mathrm{~min}$ in saline containing $6 \mathrm{mM} \mathrm{ACC}$. After a thorough washing, basal $\mathrm{pH}_{\mathrm{i}}$ was measured for 10 min (every $5 \mathrm{~min}$ ) with the jejunal villi exposed to oxygenated prewarmed buffer
A without glucose. The fluorescence emission intensities were measured every $5 \mathrm{~min}$ at 100,200 and $300 \mu \mathrm{m}$ from the villus tip, then the solution was switched to buffer B without glucose, and recording was resumed for another $15 \mathrm{~min}$. Fluorescence light scattering was too strong due to the mucus accumulation to continue for longer observation periods. SNARF-1 was excited at $780 \mathrm{~nm}$, and the emission was collected at $580 \mathrm{~nm}(523-605 \mathrm{~nm})$ and $640 \mathrm{~nm}(610$ $700 \mathrm{~nm}$ ), using a two-photon laser scanning microscope with an upright Leica TCS SP2 confocal microscope with a $20 \times$ water immersion objective and a MaiTai Ti:sapphire-pulsed laser (Spectra-Physics), as previously described [7, 46].

\section{Epithelial surface pH measurement in the jejunum}

Surface $\mathrm{pH}$ assessment was performed as previously described [45], with modification to adjust the technique to the jejunum. The exposed jejunal mucosa was overlaid with different buffers containing the cell impermeable $5 \mu \mathrm{M}$ SNARF-5 free acid and fluorescence scans were performed every $50 \mu \mathrm{m}$ from the epithelium surface to the tips of villi, and every $100 \mu \mathrm{m}$ from the tips of villi to the solution surface.

\section{Calibration of the SNARF-1 and SNARF-5 ratio to $\mathrm{pH}_{i}$}

An in vitro calibration curve was made using different $\mathrm{pH}$ solutions as has been described previously [46]. The linear range of the calibration curve was taken to measure the intracellular and extracellular $\mathrm{pH}$.

Statistical analysis

Descriptive data were reported as mean \pm SEM. Data between two treatment groups were compared using a two-tailed unpaired Student's $t$-test assuming equal variances between two groups. Data from multiple treatment groups were compared using a one-way analysis of variance with a post hoc Tukey's $t$-test. A $p$ value of $<0.05$ was considered statistically significant.

\section{Results}

Fluid absorptive rate and $\mathrm{pH}$ change of effluent in WT jejunum before and after removal of luminal $\mathrm{Cl}^{-}$, or luminal $\mathrm{Na}^{+}$

WT jejunum absorbed fluid and acidified the unbuffered perfusate (Fig. 1a, b; data shown for the C57BL/6 strain but qualitatively the same data were obtained for the $\mathrm{FVB} / \mathrm{N}$ strain). $\mathrm{Cl}^{-}$removal from the perfusate resulted in a decrease in the fluid absorptive rate and a stronger acidification of the effluent (Fig. 1a, b), consistent with the concept that $\mathrm{Cl}^{-}$ 
a
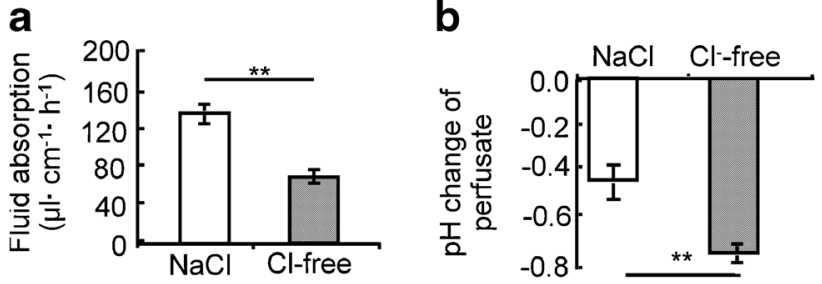

C

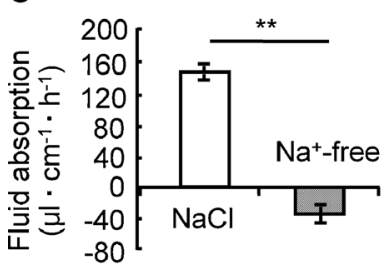

e

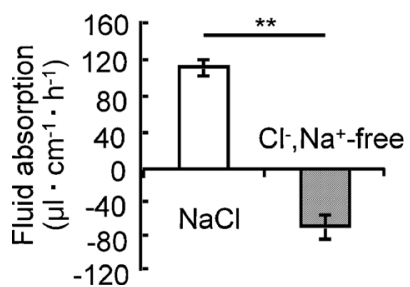

d

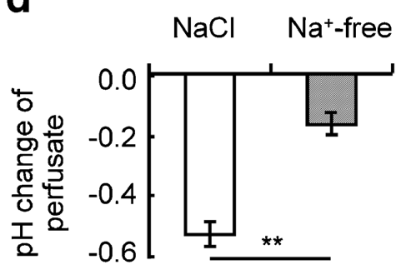

f

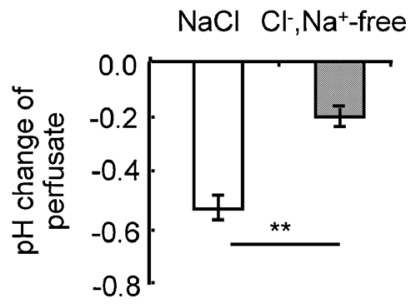

Fig. 1 Fluid absorptive rate and $\mathrm{pH}$ change between the influent (unbuffered saline) and the effluent solution in perfused WT jejunal loops before and after removal of luminal $\mathrm{Cl}^{-}$or luminal $\mathrm{Na}^{+}$, or both. $\mathbf{a}, \mathbf{b}$ Removal of $\mathrm{Cl}^{-}$from the luminal perfusate (substitution by gluconate) reduced fluid absorptive rate by $\sim 50 \%$ (a) and caused a stronger acidification of the effluent (b), suggesting the inhibition of $\mathrm{a}^{-}$/ $\mathrm{HCO}_{3}{ }^{-}$exchange process. c, d Removal of $\mathrm{Na}^{+}$from the luminal perfusate by substitution with $N$-methyl-D-glucamine (NMDG) completely abolished absorption (c) and caused a lesser degree of acidification suggesting the inhibition of a $\mathrm{Na}^{+} / \mathrm{H}^{+}$exchange process. $\mathbf{e}$, f Removal of both $\mathrm{Na}^{+}$and $\mathrm{Cl}^{-}$caused the tissue to secrete more fluid than just with $\mathrm{Na}^{+}$removal (e), but did not further change the $\mathrm{pH}$ of the effluent. $* * p<0.01, n=5$

absorption occurs in exchange for $\mathrm{HCO}_{3}{ }^{-}$, and that this $\mathrm{Cl}^{-} /$ $\mathrm{HCO}_{3}{ }^{-}$exchange process enhances fluid absorption. $\mathrm{Na}^{+}$ removal from the perfusate resulted in a low rate of fluid secretion, and less acidification of the perfusate (Fig. 1c, d). This suggests that the major reason for perfusate acidification is $\mathrm{Na}^{+} / \mathrm{H}^{+}$exchange. The removal of $\mathrm{Na}^{+}$and $\mathrm{Cl}^{-}$resulted in a slightly stronger loss of fluid into the lumen, suggesting that a fluid secretory process may have been stimulated under these circumstances (Fig. 1e, f).

Fluid absorptive rate and $\mathrm{pH}$ change of effluent in NHE2-, NHE3-, DRA- and PAT-1-deficient jejunum

The KO mice from each strain were compared with the respective WT littermates or closely related mice, which were cohoused and received the same diet. The diet was different for DRA- and NHE3-deficient mice and their respective controls, which will explain some of the differences in WT absorptive

rates between the different strains. NHE2-deficient jejunum did not result in a different fluid absorptive rate compared to WT littermates and the acidification of the effluent was even slightly stronger (Table 1, first two rows). The NHE2deficient mice displayed neither an upregulation of NHE3 expression, nor an increase in aldosterone levels. NHE2deficient villous enterocytes displayed a lower steady-state $\mathrm{pH}_{\mathrm{i}}$ than littermates (Table $\mathrm{S} 3$ ), which possibly explains the slightly stronger acidification of the perfusate. The results shed doubts on a proposed role of NHE2 in jejunal fluid absorption, at least in mice.

NHE3-deficient mice had a significantly decreased jejunal fluid absorptive rate and a significantly stronger alkalinisation of the effluent (Table 1, rows 3 and 4), consistent with the loss of a $\mathrm{Na}^{+} / \mathrm{H}^{+}$exchange process in the apical membrane of the jejunal enterocytes. $\mathrm{Cl}^{-}$removal reversed the alkalinisation, but did not further decrease the residual fluid absorptive rate (data not shown).

DRA-deficient jejunum displayed a significant reduction in jejunal fluid absorption and a significantly stronger acidification of the effluent, consistent with the function of DRA as a $\mathrm{Cl}^{-} / \mathrm{HCO}_{3}{ }^{-}$exchanger, absorbing $\mathrm{Cl}^{-}$in exchange for $\mathrm{HCO}_{3}{ }^{-}$(Table 1, rows 5 and 6).

PAT-1-deficient jejunum also displayed a significantly lower fluid absorptive rate than WT, but, surprisingly, a less degree of acidification of the jejunal effluent. These results

Table 1 Fluid absorptive rate and $\mathrm{pH}$ change of the effluent in NHE2-, NHE3-, DRA- and PAT-1-deficient jejunum

Fluid absorption $\left(\mu \mathrm{cm}^{-1} \mathrm{~h}^{-1}\right) \mathrm{pH}$ change after perfusion

\begin{tabular}{cccc}
\hline NHE2 & WT & $158.0 \pm 14.7$ & $-0.38 \pm 0.08$ \\
& KO & $161.8 \pm 14.4$ & $-0.50 \pm 0.09$ \\
NHE3 & WT & $147.7 \pm 4.9$ & $-0.29 \pm 0.07$ \\
& KO & $87.3 \pm 10.3^{*}$ & $0.27 \pm 0.09^{*}$ \\
DRA & WT & $129.6 \pm 10.5$ & $-0.58 \pm 0.10$ \\
& KO & $85.6 \pm 5.9^{*}$ & $-1.11 \pm 0.07^{*}$ \\
PAT-1 & WT & $145.9 \pm 9.0$ & $-0.33 \pm 0.05$ \\
& KO & $107.1 \pm 4.9^{* *}$ & $-0.14 \pm 0.06^{*}$ \\
\end{tabular}

The values give the jejunal fluid absorptive rates during perfusion with prewarmed isotonic unbuffered saline, $\mathrm{pH}$ titrated to 7.4 , and the change of the $\mathrm{pH}$ of the effluent in comparison to the inflowing solution, in $\mathrm{pH}$ units No significant difference in fluid absorptive rate or acidification of the effluent was seen between NHE2 KO and WT jejunum, $n=4$. NHE3 deletion resulted in a reduction of fluid absorptive rate by $40.9 \pm 6.8 \%$ compared to WT, and a significantly stronger alkalinisation of the effluent. $* p<0.05, n=4$. DRA deletion resulted in a $26.8 \pm 5.2 \%$ decrease in fluid absorptive rate, and a stronger acidification of the effluent compared to WT. ${ }^{*} p<0.05, n=5-7$. PAT- 1 deletion also resulted in a decrease in fluid absorptive rate by $25.1 \pm 4.1 \%$, but — surprisingly less acidification than WT jejunum. ${ }^{*} p<0.05, n=10$. These results are inconsistent with the assumption of PAT-1 as well as DRA operating as $\mathrm{Cl}^{-}{ }_{\text {in }} / \mathrm{HCO}_{3}{ }^{-}$out exchangers under the experimental conditions

${ }^{*} p<0.05,{ }^{*} p<0.01, * * * p<0.001$, WT compared with KO group in the same genotype mice 
suggest that PAT-1 plays a role in jejunal fluid absorption, but does not transport acid/base moieties in the same direction as DRA (Table 1, rows 7 and 8).

Switch from oxygenated saline to $\mathrm{CO}_{2} / \mathrm{HCO}_{3}{ }^{-}$buffered saline strongly enhances jejunal fluid absorption

In an attempt to mimic postprandial ionic conditions in the upper GI tract after the pancreatic juice has mixed with the low $\mathrm{pH}$ milieu of the upper duodenum, we switched the unbuffered oxygenated saline to a $5 \% \mathrm{CO}_{2} / \mathrm{HCO}_{3}{ }^{-}$buffered saline of identical $\mathrm{pH}$ (7.4). This manoeuvre resulted in a dramatic stimulation of jejunal fluid absorption, both in the presence and the absence of carbonic anhydrase 2 (CA2) expression (Fig. 2a). The absence of CA2 expression resulted in a more acidic $\mathrm{pH}$ of the effluent compared to WT during unbuffered saline perfusion (Fig. 2b), suggesting that CA2 may augment the generation of $\mathrm{HCO}_{3}{ }^{-}$for DRA-mediated $\mathrm{Cl}^{-}$ absorption, but that its absence can be compensated for (because no significant reduction in fluid absorption was observed in $\mathrm{CA} 2 \mathrm{KO}$ compared to WT jejunum). The switch to $\mathrm{CO}_{2} / \mathrm{HCO}_{3}{ }^{-}$abolished any acidification/alkalinisation of the perfusate during the pass though the jejunal segment, probably because of its high buffer capacity.
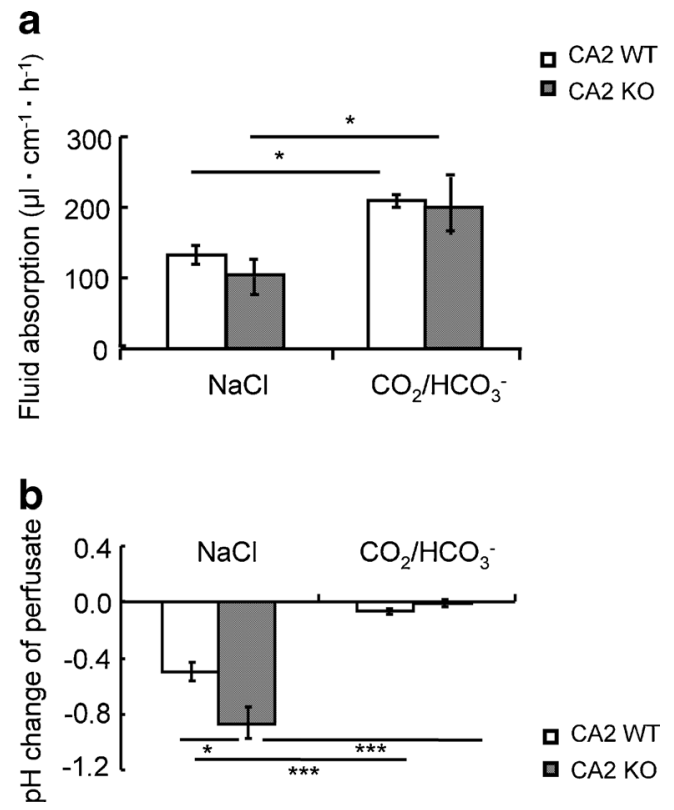

Fig. 2 Switch from oxygenated saline to $\mathrm{CO}_{2} / \mathrm{HCO}_{3}{ }^{-}$buffered saline strongly enhances jejunal fluid absorption. a $\mathrm{A}$ switch of the luminal perfusate from unbuffered saline, $\mathrm{pH} 7.4$, to a $5 \% \mathrm{CO}_{2} / 24 \mathrm{mM} \mathrm{HCO}_{3}^{-}$containing saline, $\mathrm{pH} 7.4$, resulted in a strong and persistent increase in fluid absorptive rate. The absence of CA2 caused a variable decrease of fluid absorptive rate (a) and a significantly higher acidification of the effluent (b), but the increase in fluid absorption after the switch to $\mathrm{CO}_{2} / \mathrm{HCO}_{3}{ }^{-}$was not significantly different from WT. ${ }^{*} p<0.05, * * p<0.01 . n=5$
The $\mathrm{CO}_{2} / \mathrm{HCO}_{3}{ }^{-}$-induced increase in jejunal fluid absorption is reduced strongly in NHE3- and PAT-1-deficient mice, but only mildly in DRA-deficient mice

We next investigated the $\mathrm{CO}_{2} / \mathrm{HCO}_{3}{ }^{-}$-induced fluid absorptive response in mice with genetic ablation or pharmacological inhibition of NHE3, and found that in the absence of NHE3 expression (Fig. 3a), the $\mathrm{CO}_{2} / \mathrm{HCO}_{3}{ }^{-}$induced increase in fluid absorptive rate was virtually abolished. When $20 \mu \mathrm{M}$ of the NHE3 inhibitor S1611 was added prior, as well as together, with $\mathrm{CO}_{2} / \mathrm{HCO}_{3}{ }^{-}$, the $\mathrm{CO}_{2} /$ $\mathrm{HCO}_{3}{ }^{-}$induced increase in fluid absorption was also greatly diminished (see legend to Fig. 3 for values). This demonstrates the necessity of NHE3 activation for $\mathrm{CO}_{2} /$ $\mathrm{HCO}_{3}{ }^{-}$induced fluid absorption.

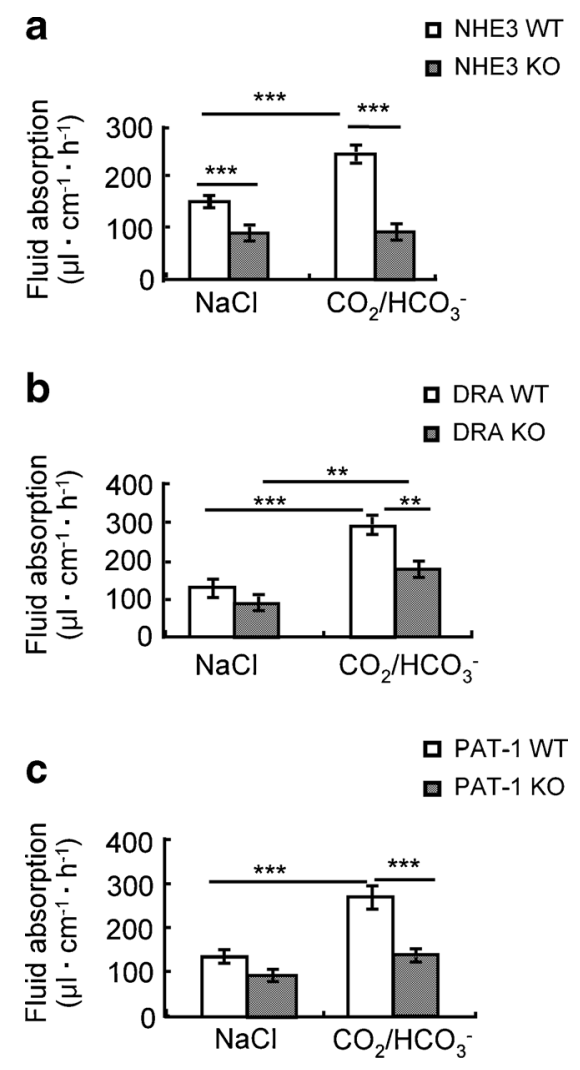

Fig. 3 The $\mathrm{CO}_{2} / \mathrm{HCO}_{3}{ }^{-}$-induced increase in fluid absorption is strongly reduced in NHE3- and PAT-1-deficient and to a lesser degree in DRAdeficient jejunum. a NHE3 KO mice did not display a change in the fluid absorptive rate when the luminal perfusate was switched to $\mathrm{CO}_{2} / \mathrm{HCO}_{3}{ }^{-}$containing saline, $\mathrm{pH}$ 7.4. A strong inhibition of $\mathrm{CO}_{2} / \mathrm{HCO}_{3}{ }^{-}$induced fluid absorption was also observed when $20 \mu \mathrm{M}$ of the specific NHE3 inhibitor S1611 was applied prior to the solution change $(137 \pm 14.2$

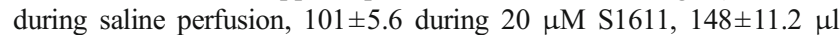
$\mathrm{cm}^{-1} \mathrm{~h}^{-1}$ during $\mathrm{S} 1611$ and $\left.\mathrm{CO}_{2} / \mathrm{HCO}_{3}{ }^{-}\right)$. b The switch to $\mathrm{CO}_{2} / \mathrm{HCO}_{3}{ }^{-}$ elicited an increase in fluid absorption in DRA KO mice that was, in \% from basal, insignificantly different from the WT increase. c In contrast, the $\mathrm{CO}_{2} / \mathrm{HCO}_{3}{ }^{-}$-induced increase was significantly reduced in PAT KO compared to WT jejunum. The percentage values are given in the text. $* * p<0.01, * * * p<0.001 . n=4-5$ 
In the absence of DRA expression, the basal fluid absorptive rate was lower, but the increase in fluid absorptive rate by $\mathrm{CO}_{2} / \mathrm{HCO}_{3}{ }^{-}$was robust $(226.9 \pm 47.2 \%$ of basal in DRA KO vs. $282.0 \pm 80.6 \%$ of basal in WT), although the overall fluid absorptive rate in $\mathrm{CO}_{2} / \mathrm{HCO}_{3}{ }^{-}$remained below that of WT jejunum (Fig. 3b).

In the absence of PAT-1 expression, the basal fluid absorptive rate was also lower $\left(131.7 \pm 9.9 \mu \mathrm{cm}^{-1} \mathrm{~h}^{-1}\right.$ in WT vs. $94.1 \pm 9.2 \mu \mathrm{cm}^{-1} \mathrm{~h}^{-1}$ in PAT-1 KO), albeit less strongly than in the absence of DRA. The $\mathrm{CO}_{2} / \mathrm{HCO}_{3}{ }^{-}$-induced increase in fluid absorption was strongly reduced (203.3 $\pm 19.6 \%$ in WT vs. $144.9 \pm 5.2 \%$ in KO) (Fig. 3c).

$\mathrm{Cl}^{-}$removal from the luminal perfusate abolishes the $\mathrm{CO}_{2} / \mathrm{HCO}_{3}{ }^{-}$induced increase in fluid absorptive rate in PAT1-deficient, but not in DRA-deficient jejunum

In order to find out whether the two Slc26 family members may import different anions during the $\mathrm{CO}_{2} /$ $\mathrm{HCO}_{3}{ }^{-}$-induced increase in fluid absorptive rate, we substituted the $\mathrm{Cl}^{-}$ions in the luminal perfusate for gluconate. This significantly reduced the fluid absorptive rate in the WT, as well as the PAT-1-deficient jejunum, but not in the DRA-deficient jejunum (Fig. 4a, b, middle two bars). When the perfusate was then switched to one containing $\mathrm{CO}_{2} / \mathrm{HCO}_{3}{ }^{-}$but no $\mathrm{Cl}^{-}$, there was a significant increase of fluid absorptive rate in the WT and the DRAdeficient jejunum, but not in PAT-1-deficient jejunum (Fig. 4a, b, right two bars). Luminal $\mathrm{Cl}^{-}$substitution resulted in increased acidification of the effluent in WT and PAT-1-deficient jejunum, but did not change the acidification in effluent from DRA-deficient jejunum (Table 2).

In the absence of CA2, no significant reduction of fluid absorption compared to WT was observed during saline perfusion (Fig. 4c, left bars), but the removal of $\mathrm{Cl}^{-}$did not result in a significant decrease in absorptive rate in CA2 $\mathrm{KO}$ jejunum, whereas it did so in WT (Fig. 4c, middle bars). The relative $\mathrm{CO}_{2} / \mathrm{HCO}_{3}{ }^{-}$-induced stimulation of fluid absorption was not significantly different between CA2 WT and KO mice (Fig. 4c, right bars). Similar to the results of Fig. 3, the changes in fluid absorption seen in the absence of CA2 parallel those seen in the DRA KO jejunum, but are distinctly different from those in the PAT-1 KO jejunum (Table 2).

Taken together, these results suggest that DRA, but not PAT-1, is responsible for the $\mathrm{Cl}^{-}$-dependent fluid absorption as well as alkalinisation of the jejunal effluent, and that CA2 augments $\mathrm{HCO}_{3}{ }^{-}$i generation for DRA-mediated exchange against $\mathrm{Cl}^{-}$. In contrast, PAT-1 is necessary for the $\mathrm{Cl}^{-}$-independent part of $\mathrm{CO}_{2} / \mathrm{HCO}_{3}{ }^{-}$-induced fluid absorption, possibly by direct $\mathrm{HCO}_{3}{ }^{-}$absorption from the lumen.
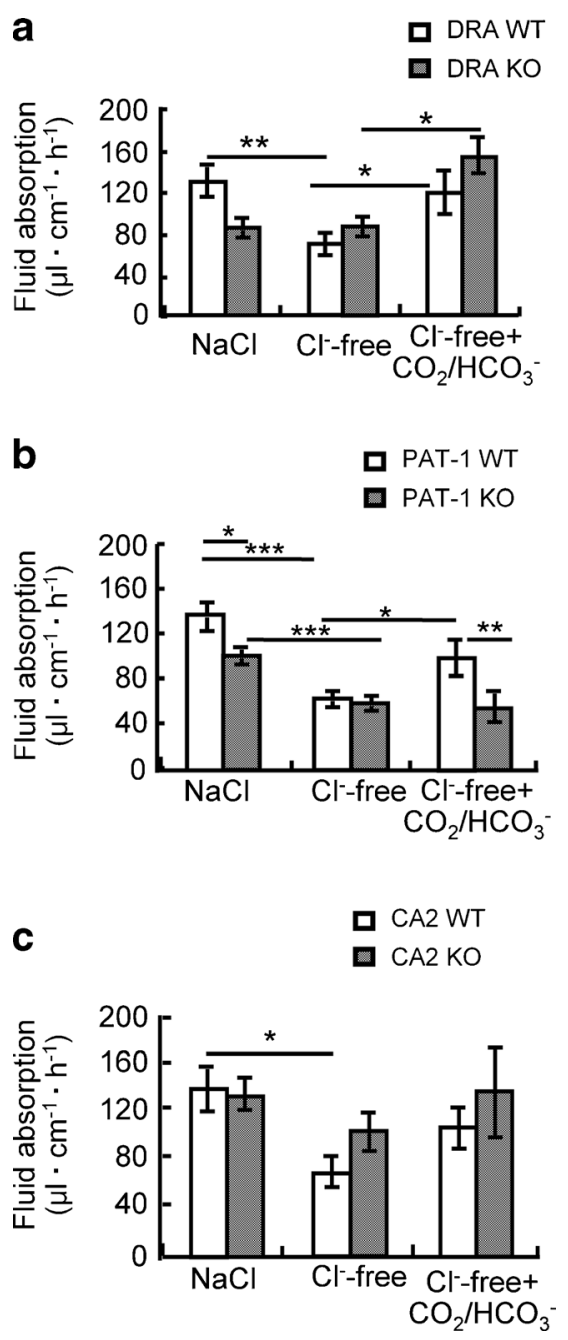

Fig. $4 \mathrm{Cl}^{-}$removal from the luminal perfusate abolished the $\mathrm{CO}_{2} /$ $\mathrm{HCO}_{3}{ }^{-}$-induced increase in fluid absorptive rate in PAT1-deficient but not in DRA-deficient jejunum. In order to inhibit apical $\mathrm{Cl}^{-}$in $/ \mathrm{HCO}_{3}{ }^{-}$out exchange, $\mathrm{Cl}^{-}$was removed for the luminal perfusate. a $\mathrm{Cl}^{-}$removal resulted in a significant decrease in the fluid absorptive rate in the absence of $\mathrm{CO}_{2} / \mathrm{HCO}_{3}{ }^{-}$in WT jejunum, but not in DRA-deficient jejunum. The $\mathrm{CO}_{2} / \mathrm{HCO}_{3}^{-}$-induced increase in the absorptive rate was not different in WT and DRA-deficient jejunum. b In contrast, $\mathrm{Cl}^{-}$removal caused a similar decrease in fluid absorptive rate in PAT-1 KO and WT littermate jejunum, but no $\mathrm{CO}_{2} / \mathrm{HCO}_{3}{ }^{-}$-induced increase in the fluid absorptive rate was observed in PAT-1 KO jejunum. c The pattern observed in CA2 KO mice was similar to that in DRA KO but not in PAT-1 KO mice, suggesting that CA2 activity may be important to generate $\mathrm{HCO}_{3}{ }^{-}$destined for export through DRA. $* p<0.05, * * p<$ $0.01, * * * p<0.001, n=4-6$

$\mathrm{Na}^{+}$removal from the perfusate resulted in a reversal of the absorptive to a secretory state of the jejunum, but $\mathrm{CO}_{2} / \mathrm{HCO}_{3}{ }^{-}$was able to reverse secretion in a PAT-1 dependent fashion

We next investigated the effect of $\mathrm{Na}^{+}$removal from the luminal perfusate on basal and $\mathrm{CO}_{2} / \mathrm{HCO}_{3}{ }^{-}$-induced fluid absorption and the effect of PAT-1 deletion. $\mathrm{Na}^{+}$removal resulted in a reversal of fluid absorption to secretion 
Table 2 Effluent $\mathrm{pH}$ change after luminal $\mathrm{Cl}^{-}$removal in the different genotypes

\begin{tabular}{llll}
\hline & & \multicolumn{2}{l}{$\mathrm{pH}$ change after perfusion } \\
\cline { 3 - 4 } & & $\mathrm{NaCl}$ & $\mathrm{Cl}^{-}$-free \\
\hline PAT-1 & WT & $-0.38 \pm 0.07$ & $-0.71 \pm 0.03 * * *$ \\
& KO & $-0.21 \pm 0.03^{\#}$ & $-0.72 \pm 0.04 * * *$ \\
DRA & WT & $-0.56 \pm 0.15$ & $-0.77 \pm 0.04$ \\
& KO & $-1.07 \pm 0.09^{\# \# \#}$ & $-0.89 \pm 0.04$ \\
CA2 & WT & $-0.60 \pm 0.11$ & $-0.74 \pm 0.08$ \\
& CO & $-0.77 \pm 0.16$ & $-0.78 \pm 0.08$ \\
\hline
\end{tabular}

Effluent $\mathrm{pH}$ decreased after luminal $\mathrm{Cl}^{-}$removal in WT and PAT-1 KO jejunum, but not in DRA- or CA2-deficient jejunum. This suggests that luminal $\mathrm{Cl}^{-}$removal inhibits DRA-mediated, CA2-facilitated $\mathrm{HCO}_{3}{ }^{-}$ export

${ }^{\#} p<0.05,{ }^{\# \#} p<0.001$, when compared with the WT in the same perfusion solution

${ }^{*} p<0.05,{ }^{* *} p>0.01,{ }^{* * *} p>0.001$, when compared with the $\mathrm{NaCl}$ group in the same genotype mice

(Fig. 5a, middle panel) in WT mice and the effect was slightly less in PAT-1 KO mice. $\mathrm{Na}^{+}$removal resulted in a decrease in the acidification of the effluent (Fig. 5b), but did not result in alkalinisation, as does NHE3 KO (see Table 1). When the luminal perfusate was switched to $\mathrm{CO}_{2} / \mathrm{HCO}_{3}{ }^{-}$, a small but significant reduction in the fluid secretory rate was observed
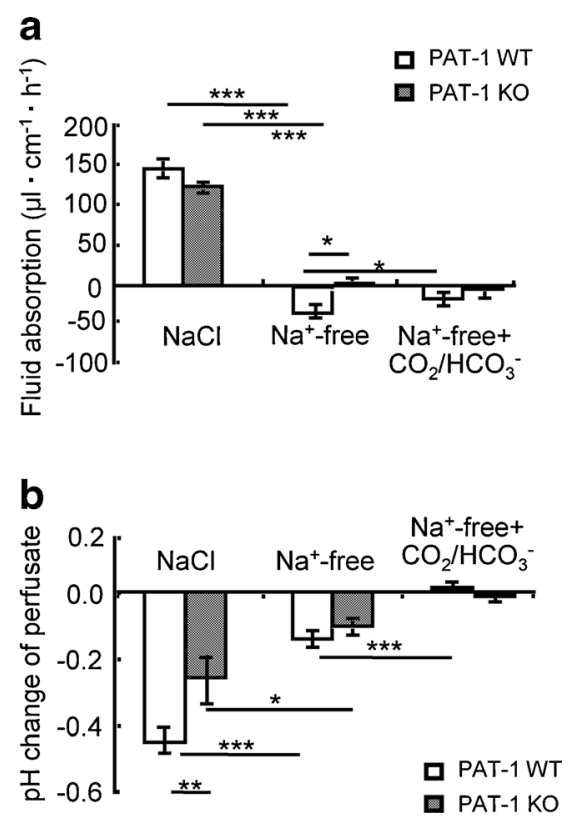

Fig. $5 \mathrm{Na}^{+}$removal from the perfusate resulted in a reversal of the absorptive to a secretory state of the jejunum, but $\mathrm{CO}_{2} / \mathrm{HCO}_{3}{ }^{-}$was able to reverse partially secretion in a PAT-1 dependent fashion. a As shown in Fig. 1, the removal of $\mathrm{Na}^{+}$from the perfusate resulted in fluid secretion in the WT jejunum. This secretory rate was diminished by the switch to $\mathrm{CO}_{2} /$ $\mathrm{HCO}_{3}^{-}$, but only in WT jejunum. This suggest that a very small $\mathrm{Na}^{+}-$ independent ion import, most likely $\mathrm{HCO}_{3}{ }^{-}$, is possible even in the absence of $\mathrm{Na}^{+}$. $\mathbf{b ~ N a}{ }^{+}$-removal acidified the effluent both in WT and PAT-1 KO jejunum. ${ }^{*} p<0.05,{ }^{* *} p<0.01,{ }^{* * *} p<0.001, n=3-6$ in WT but not in PAT-1 KO jejunum, suggesting that PAT-1 activity may be able to absorb some fluid even in the absence of luminal $\mathrm{Na}^{+}$.

Switch from oxygenated saline to $\mathrm{CO}_{2} / \mathrm{HCO}_{3}{ }^{-}$buffered saline causes a persistent decrease in jejunal villous enterocyte $\mathrm{pH}_{\mathrm{i}}$ in vitro and in vivo

To be able to interpret the findings from the fluid absorption experiments, it is important to know the jejunal villous enterocyte $\mathrm{pH}_{\mathrm{i}}$ before and after the switch to a $\mathrm{CO}_{2} / \mathrm{HCO}_{3}{ }^{-}$ buffered perfusate. We used several different techniques to accomplish this task. We firstly used microdissected BCECFloaded jejunal villi, which have the advantage of very good access of the perfusate to the epithelial cell surface, as well as very exact $\mathrm{pH}$ calibration, but the disadvantage that the lamina propria is not separately perfused, and access of the perfusate to the basolateral side of the cell may be delayed. Jejunal enterocyte steady-state $\mathrm{pH}_{\mathrm{i}}$ was measured both in the absence and presence of glucose in the bath, and was significantly more alkaline in the absence of glucose in the perfusate, as well as in the absence of $\mathrm{CO}_{2} / \mathrm{HCO}_{3}{ }^{-}$(Fig. S1). Steady-state $\mathrm{pH}$ is the $\mathrm{pH}$ after long term incubation in the respective buffer. We also measured the steady-state $\mathrm{pH}_{\mathrm{i}}$ in enterocytes within microdissected villi in the different $\mathrm{KO}$ and WT strains, in the presence of glucose (Table S3).

A switch of the solution from $\mathrm{O}_{2}$-gassed, Hepes buffered to a $\mathrm{CO}_{2} / \mathrm{HCO}_{3}{ }^{-}$solution of identical $\mathrm{pH}(7.4)$ resulted in enterocyte acidification to a new, significantly more acidic $\mathrm{pH}_{\mathrm{i}}$, and the degree of acidification after switching from Hepes $/ \mathrm{O}_{2}$ to $\mathrm{CO}_{2} / \mathrm{HCO}_{3}{ }^{-}$was not significantly different in DRA WT and KO, as well as in PAT-1 WT and KO jejunum (Fig. S2).

The in vitro experiments in microdissected villi have the shortcoming of a lack of separate control over the ionic milieu at the basolateral side of the cells. We therefore performed experiments in SNARF-1-loaded, exteriorised, vascularly perfused jejunal villi of anaesthetised mice, where the ionic conditions near the basolateral membrane are likely to be similar to those measured in the blood. The experiments confirmed a persistent decrease of steady-state $\mathrm{pH}_{\mathrm{i}}$ after switch from oxygenised saline to $\mathrm{CO}_{2} / \mathrm{HCO}_{3}{ }^{-}$buffered saline, both in WT as well as in the PAT-1 KO jejunum (Fig. S3, and Fig. 6a).

Switch from oxygenated saline to $\mathrm{CO}_{2} / \mathrm{HCO}_{3}{ }^{-}$buffered saline causes an increase in surface $\mathrm{pH}$

We also assessed the surface $\mathrm{pH}$ in the mucus layer close to the apical surface of the villous enterocytes. The thickness of the mucus layer was assessed with fluorescent beads that are large enough to settle on top of the mucus gel [45]. When a slightly buffered (300 $\mu \mathrm{M}$ Hepes/Tris) saline, $\mathrm{pH}$ 7.4, containing 
Fig. 6 Switch from oxygenated saline to $\mathrm{CO}_{2} / \mathrm{HCO}_{3}{ }^{-}$buffered saline causes a persistent decrease in jejunal villous enterocyte $\mathrm{pH}_{\mathrm{i}}$ and an increase in the surface $\mathrm{pH}$ in vivo. a A significant decrease in $\mathrm{pH}_{\mathrm{i}}$ was observed both in PAT$1 \mathrm{KO}$ and $\mathrm{WT}$ jejunum in vivo (data shown for $100 \mu \mathrm{m}$ from villus tip). b At the same time, the surface $\mathrm{pH}$ immediately external to the villous enterocytes strongly increased during the switch. Here, the surface $\mathrm{pH}$ is shown $10 \mathrm{~min}$ after the solution was layered on top of the mucosa (for $\mathrm{pH}$ values measured at different distances from the villus tip see Fig. S3). Open circles: acidic $\mathrm{pH}$ along the villus in an unbuffered solution. Open squares: surface $\mathrm{pH}$ is acidic at the crypt opening and becomes more alkaline toward the tip in a strongly buffered Hepes/ Tris $\mathrm{O}_{2}$ solution. Closed circles: upon switch to $\mathrm{CO}_{2} / \mathrm{HCO}_{3}{ }^{-}$, the surface $\mathrm{pH}$ is quite alkaline along the villus axis, even at the base of the villi, $n=3-5$
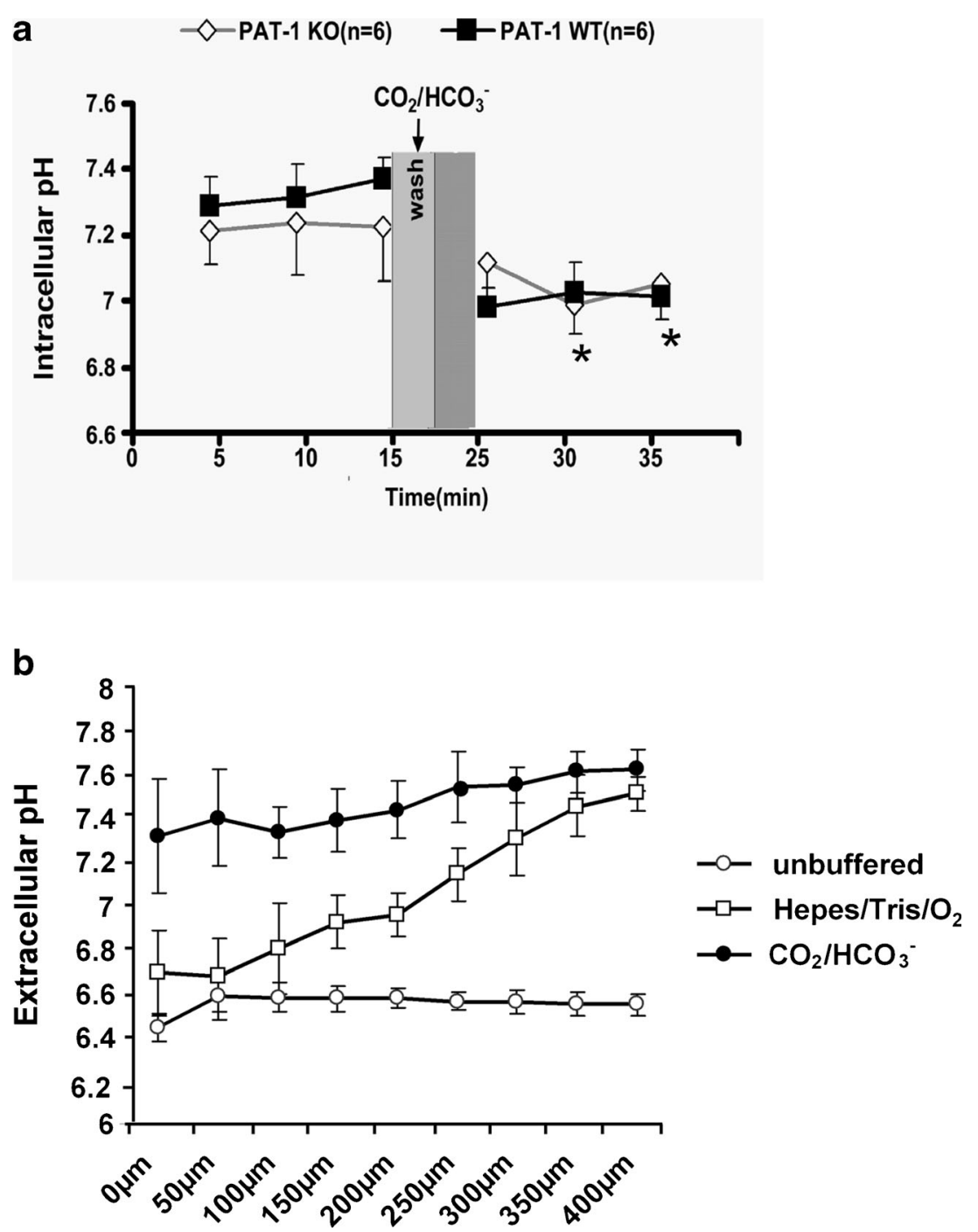

SNARF-5, was layered on top of the mucosa and fluorescence scanned immediately after stabilization of villus movement, the surface $\mathrm{pH}$ at the surface of the crypts was found to be surprisingly acidic, and became more alkaline in the mucus gel towards to tip of the villi, but did not reach pH 7.4 (Fig. 6b, open circles, and Fig. S3). This indicated to us that proton extrusion and $\mathrm{CO}_{2}$ diffusion immediately overwhelmed the small buffer capacity of the fluid component above the mucosa. Even when strongly Hepes/Tris (22 mM) buffer A was overlaid, the $\mathrm{pH}$ near the cryptal openings was still acidic (Fig. 6b, open squares). This suggests that the crypts secrete little $\mathrm{HCO}_{3}{ }^{-}$under the conditions of these experiments, despite sufficient blood $\mathrm{HCO}_{3}{ }^{-}$(see Table S1), and that the extracellular $\mathrm{pH}$ at the basal part of the villi is relatively acidic. After the perfusate was changed to $\mathrm{CO}_{2} / \mathrm{HCO}_{3}{ }^{-}$buffered saline, the surface $\mathrm{pH}$ was significantly higher along the whole length of the villi, despite a lower $\mathrm{pH}_{\mathrm{i}}$ (Fig. 6b, closed circles). While the ratios of mucosa/luminal fluid differ somewhat during experimental conditions of the two photon measurements and the single pass perfusion, we tried to make them as comparable as possible. Both experimental series indicate that during saline perfusion, a considerable proton gradient into the villous enterocytes exists (compare the villus enterocyte $\mathrm{pH}_{\mathrm{i}}$ in Hepes $/ \mathrm{O}_{2}$ in Figs. 6a, $7 \mathrm{~d}$ and $8 \mathrm{~d}$, where $\mathrm{pH}_{\mathrm{i}}$ is $~ 7.4$ in PAT-1 and DRA WT, 7.55 in DRA KO and 7.2 in PAT-1 KO mice, with the extracellular $\mathrm{pH}$ measurements in the unbuffered solution of approx. 6.7), whereas a considerable bicarbonate gradient into the enterocytes exists after the switch to $\mathrm{CO}_{2} / \mathrm{HCO}_{3}{ }^{-}$(compare the $\mathrm{pH}_{\mathrm{i}}$ of approx 7.0 in Fig. 6a with the $\mathrm{pH}_{\mathrm{o}}$ of 7.4-7.6 in Fig. 6b, closed circles).

Enterocyte $\mathrm{pH}_{\mathrm{i}}, \mathrm{NHE} 3$ transport activity and brush border membrane localization in PAT-1- and DRA-deficient jejunal enterocytes

The low $\mathrm{pH}_{\mathrm{i}}$ of PAT-1-deficient enterocytes and the importance of PAT-1 expression for $\mathrm{CO}_{2} / \mathrm{HCO}_{3}{ }^{-}$-induced fluid absorption 
in the presence and absence of luminal $\mathrm{Cl}^{-}$suggest that PAT-1 is involved in $\mathrm{HCO}_{3}^{-}$absorption under those circumstances. An alternative explanation for the data would be a decreased NHE3 expression, membrane abundance or activity in PAT-1deficient jejunum. We therefore studied NHE3 expression, membrane localization and acid-activated transport activity in WT, PAT-1-deficient and DRA-deficient jejunum. NHE3 mRNA expression levels were not significantly different in PAT-1-deficient and the respective WT littermate jejunum, as well as in DRA-deficient and WT jejunum, respectively (Figs. 7a and 8a). The graphs also show that in PAT-1 and DRA KO jejunum, the expression of the respective other Slc26 member is not altered compared to WT (Figs. 7a and 8a).

Immunohistochemical localization of NHE3 in WT jejunum demonstrated that most of the NHE3 immunofluorescence is found in the microvillar region in WT as well as in PAT-1deficient mice. In contrast, a significant fraction is found in the terminal web region in DRA-deficient mice (Figs. 7c and 8c). Acid-activated, S1611-sensitive NHE3-mediated proton efflux rates were not significantly different between WT and PAT-1deficient jejunum (Fig. 7b), but were significantly lower in DRA-deficient jejunal villi (Fig. 8b).

To find a reason for the difference in NHE3 brush border membrane distribution and transport activity, we measured steady-state $\mathrm{pH}_{\mathrm{i}}$ in PAT-1 KO vs. WT enterocytes (Fig. 7d) and DRA KO vs. WT (Fig. 8d). We assume that the high $\mathrm{pH}_{\mathrm{i}}$ in DRA-deficient villous enterocytes results in a higher percentage of NHE3 being localised in the terminal web/ microvillar cleft region, whereas NHE3 is predominantly microvillar in the low $\mathrm{pH}_{\mathrm{i}}$ in PAT-deficient enterocytes. The same phenomenon (high $\mathrm{pH}_{\mathrm{i}}$ and redistribution of NHE3 to terminal web region) was observed in CFTR-deficient villous enterocytes (data not shown).

\section{Discussion}

In the present study, we utilised $\mathrm{KO}$ mice for the two small intestinal apical $\mathrm{Na}^{+} / \mathrm{H}^{+}$exchangers, namely NHE2 and NHE3 [5], and the two apical $\mathrm{Cl}^{-} / \mathrm{HCO}_{3}{ }^{-}$exchangers, namely PAT-1 and DRA [50, 51], to better define the molecular mechanisms of jejunal fluid absorption. Our first step was to study jejunal absorptive rates of unbuffered saline whose inflowing $\mathrm{pH}$ was closely controlled by titration to 7.4 directly before being perfused into the isolated jejunal loop, and whose outflowing $\mathrm{pH}$ was immediately measured by $\mathrm{pH}$-stat titration. Doing so in all four $\mathrm{KO}$ mice, and comparing the results to sex-matched WT littermates, revealed that the lack of NHE2 expression did not affect jejunal fluid absorption and resulted in an even slightly more acidic $\mathrm{pH}$ of the effluent (Table 1). This suggests that NHE2, albeit highly expressed in murine jejunum, is not involved in apical $\mathrm{Na}^{+} / \mathrm{H}^{+}$exchange under the experimental circumstances. Why the steady-state $\mathrm{pH}_{\mathrm{i}}$ of NHE2 KO mice is nevertheless lower than that of WT mice (Table S2) is unclear, but may suggest that the mechanisms that activate NHE2 are not operative during absorption of isotonic saline.

The lack of NHE3 expression, on the other hand, reduced fluid absorption by half and resulted in effluent alkalinisation in a luminal $\mathrm{Cl}^{-}$-dependent manner (Table 1). This is entirely consistent with the action of NHE3 as an apical $\mathrm{Na}^{+} / \mathrm{H}^{+}$ exchanger. Correspondingly, NHE3 KO villous enterocytes have a lower steady-state $\mathrm{pH}_{\mathrm{i}}$ than WT enterocytes (Table $\mathrm{S} 2$ ). The absence of NHE3 unmasks the luminal alkalinisation by $\mathrm{Cl}^{-} / \mathrm{HCO}_{3}{ }^{-}$exchange. $\mathrm{Na}^{+}$removal from the perfusate reversed absorption to secretion and reduced luminal acidification but did not result in alkalinisation, indicating that the absence of $\mathrm{Na}^{+}$, but not the absence of NHE3, inhibits luminal $\mathrm{Cl}^{-} / \mathrm{HCO}_{3}{ }^{-}$ exchange, probably because of a strong enterocyte $\mathrm{pH}_{\mathrm{i}}$ decrease and/or cell shrinkage. The results also show that the jejunum has alternative $\mathrm{Na}^{+}$-absorptive mechanisms to NHE3, which appear to be distinct from NHE2, since the addition of HOE642 in concentrations sufficient to inhibit NHE2 does not inhibit this residual $50 \%$ absorptive rate (data not shown). The presence of these non-NHE3 $\mathrm{Na}^{+}$absorptive mechanisms was also apparent in $\mathrm{Na}^{+}$flux studies in isolated murine jejunal epithelium [16], and was EIPA sensitive and inhibited by cAMP, but not readily attributable to NHE2. We do not currently know if NHE8, also expressed in the intestine, or luminally expressed $\mathrm{Na}^{+}$bicarbonate cotransporters (NBCs), in conjunction with carbonic anhydrases at or near the brush border membrane, play a role in jejunal $\mathrm{Na}^{+}$absorption. Cation-selective tight junctions in conjunction with $\mathrm{Cl}^{-} / \mathrm{HCO}_{3}{ }^{-}$exchange may also be an alternative route of $\mathrm{Na}^{+}$absorption, since the luminal perfusate alkalinised during the residual fluid absorptive process in NHE3-deficient jejunum in vivo (Table 1).

The lack of DRA expression resulted in a reduction of fluid absorption and a stronger acidification of the effluent compared to the respective WT jejunum, which is entirely consistent with the role of DRA as a $\mathrm{Cl}^{-} / \mathrm{HCO}_{3}{ }^{-}$exchanger (Table 1). The lack of PAT-1 expression also resulted in a reduction of fluid absorption, but a lesser acidification of the effluent (Table 1). This indicates that PAT-1 and DRA may not perform the same transport function.

When we switched to $5 \% \mathrm{CO}_{2} / 24 \mathrm{mM} \mathrm{HCO}_{3}{ }^{-}$-buffered saline at an identical $\mathrm{pH}(7.4)$, there was a strong increase in fluid absorptive rates, which were somewhat higher in the first than in the second 20-min observation period, but was persistent even if we measured the rates for longer time periods (data not shown). To get insight into the underlying molecular mechanisms, we first measured the $\mathrm{CO}_{2} / \mathrm{HCO}_{3}{ }^{-}$-induced increase in fluid absorption in the different $\mathrm{KO}$ mice of this study and their respective WT littermates. In the absence of NHE2, the $\mathrm{CO}_{2} / \mathrm{HCO}_{3}{ }^{-}$-induced increase in fluid absorption was completely normal (data not shown), whereas it was abolished in the absence of NHE3 expression (Fig. 3). Pharmacological NHE3 inhibition with S1611 had a similar 

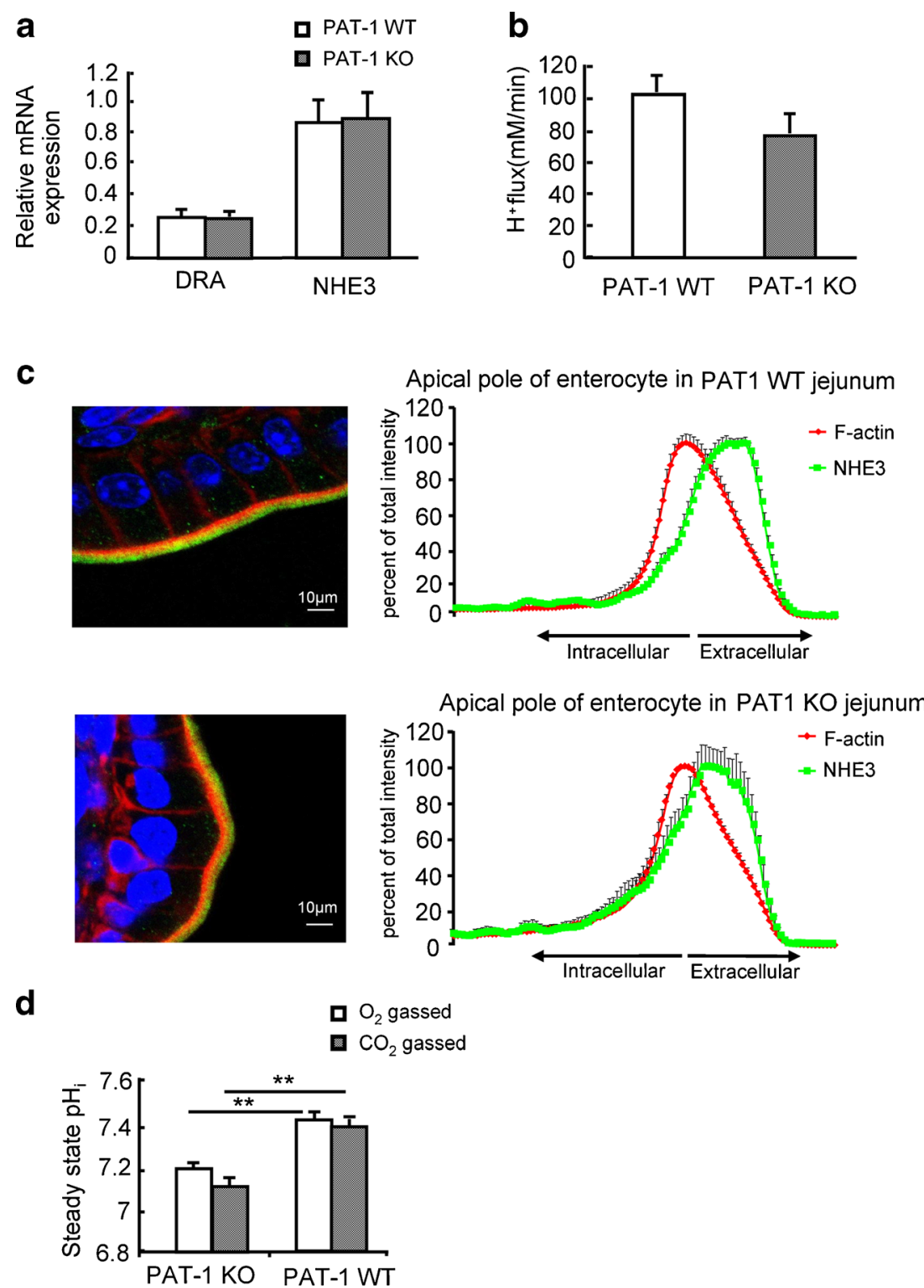

Fig. 7 Absence of jejunal PAT-1 expression results in low enterocyte $\mathrm{pH}_{\mathrm{i}}$, but not in an altered NHE3 expression, membrane localization or functional activity. a DRA and NHE3 mRNA expression levels in PAT-1 $\mathrm{KO}$ and WT jejunum. b Acid-activated NHE3 transport activity was assessed as the HOE642 insensitive, S1611-sensitive $\mathrm{Na}^{+}$-dependent proton export rate in microdissected jeunal villi of PAT-1 KO and WT enterocytes, as described in "Material and methods". No significant difference was seen between the two genotypes (b); $n=3-7, * p<0.05$. c NHE3 staining in the jejunal enterocyte brush border membrane in relation to the F-actin apical cytoskeleton (phalloidin staining), and

effect. In the absence of DRA expression, the $\mathrm{CO}_{2} / \mathrm{HCO}_{3}{ }^{-}$induced increase in fluid absorptive rate in percent of basal was only slightly lower than in WT, whereas it was strongly decreased in the absence of PAT-1 expression (Fig. 3). These experiments indicate that NHE3 and PAT-1 rather than DRA are essential for the $\mathrm{CO}_{2} / \mathrm{HCO}_{3}{ }^{-}$-stimulated increase in jejunal fluid absorption. The absence of CAII did not mimic the effect of PAT-1 but of DRA deletion (albeit less pronounced), quantitation of the relative distribution of NHE3 in \% of total brush border membrane NHE3 within the analysed area, along the terminal web-microvillar axis (left panels). The peak of the F-actin intensity indicates the microvillar cleft/terminal web zone [28]. It is evident that the majority of NHE3 is located more towards the lumen, i.e., in the microvilli, both in WT and PAT-1 KO jejunum. Eight different cellular regions (different cells, different villi) were studied from three pairs of mice. d Steady-state $\mathrm{pH}_{\mathrm{i}}$ in PAT-1 KO and WT enterocytes in the absence or presence of $\mathrm{CO}_{2} / \mathrm{HCO}_{3}{ }^{-} \cdot{ }^{*} p<0.05, n=5-7$

suggesting that CAII is required for intracellular $\mathrm{HCO}_{3}{ }^{-}$ generation and supply for DRA-mediated $\mathrm{HCO}_{3}{ }^{-}$export, but not for PAT-1 transport rate, as suggested by the data by Alvarez et al. [3] in expression systems.

In order to further clarify the mode of action of DRA and PAT-1 in $\mathrm{CO}_{2} / \mathrm{HCO}_{3}{ }^{-}$-induced jejunal fluid absorption, we removed $\mathrm{Cl}^{-}$from the luminal perfusate. This manoeuvre reduced fluid absorption by half and acidified the effluent more 
Fig. 8 Absence of jejunal DRA expression results in high enterocyte $\mathrm{pH}_{\mathrm{i}}$, a redistribution of NHE3 to the terminal web region, and a decrease in NHE3

functional activity despite slightly higher mRNA expression levels. a PAT-1 and NHE3 mRNA expression levels in DRA KO and WT jejunum; there is slightly higher NHE3 mRNA in the KO. b Acid-activated NHE3 transport activity was significantly lower in DRA KO compared to WT enterocytes. ${ }^{*} p<0.05, n=6-8$. c NHE3 staining in the jenunal enterocyte brush border membrane in relation to the Factin apical cytoskeleton (phalloidin staining), and quantitation of the relative distribution of NHE3 in \% of total brush border membrane NHE3 within the analysed area, along the terminal web-microvillar axis (left panels). It is evident that a significant fraction of NHE3 is located more towards the cell interior, i.e., in the terminal web region, in DRA KO jejunum. Eight different cellular regions (different cells, different villi) were studied from three pairs of mice. $\mathbf{d} \mathrm{pH}_{\mathrm{i}}$ was significantly higher in DRA KO villi vs. WT enterocytes
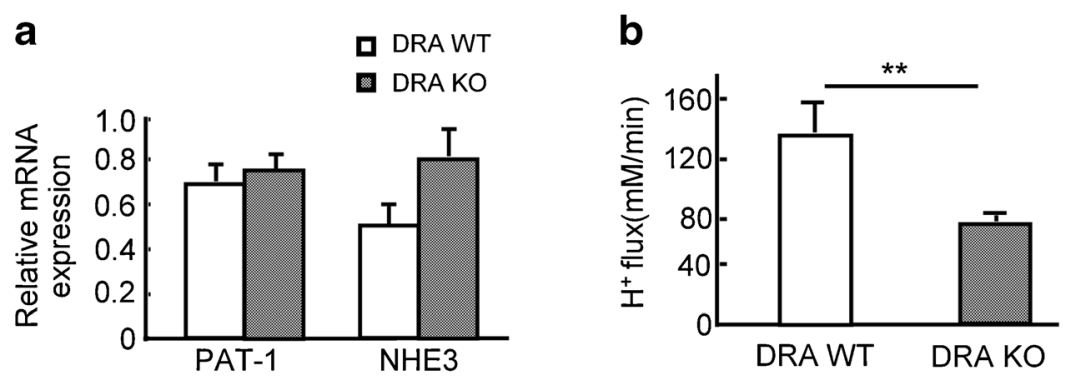

C
d
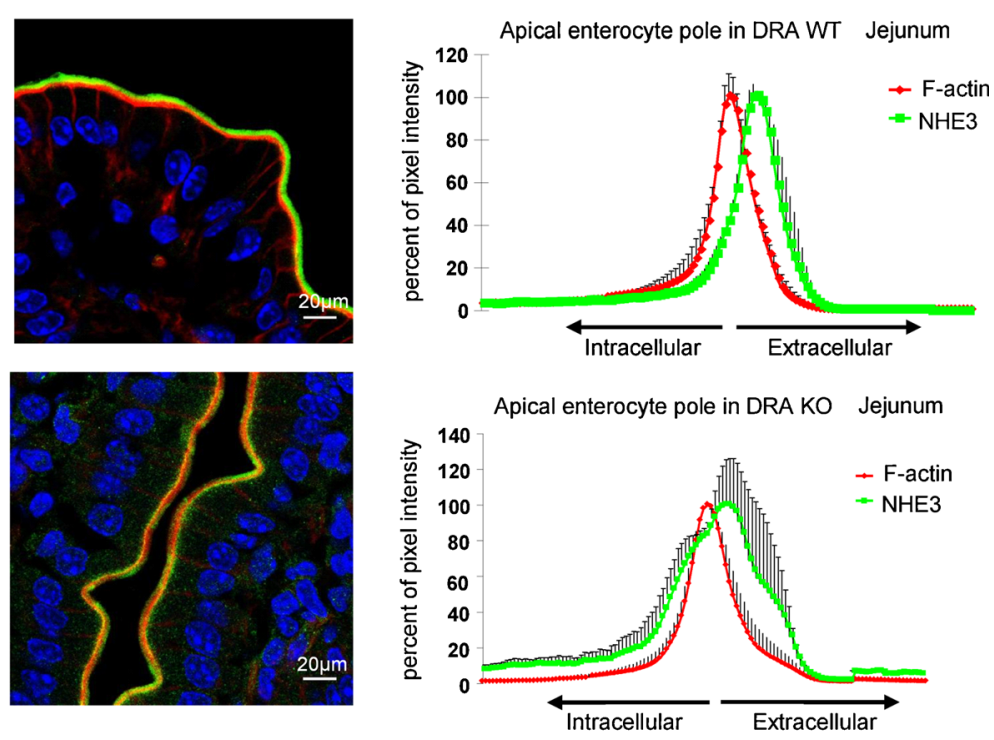

- $\mathrm{O}_{2}$ gassed

a $\mathrm{CO}_{2}$ gassed

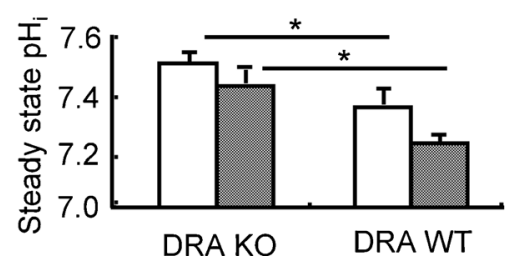

strongly than in the presence of luminal $\mathrm{Cl}^{-}$in WT, as well as PAT-1 KO jejunum, but not in DRA KO jejunum. This indicates that DRA, but not PAT-1, is responsible for $\mathrm{Cl}^{-}$-dependent jejunal fluid absorption via exchange for base, when isotonic saline is perfused through the jejunum. A switch to $5 \% \mathrm{CO}_{2} /$ $\mathrm{HCO}_{3}{ }^{-}$in the absence of luminal $\mathrm{Cl}^{-}$resulted in a significant increase of fluid secretion in WT and DRA KO, but not in PAT-1 KO jejunum (Fig. 4). These data suggest that PAT-1 is able to augment $\mathrm{CO}_{2} / \mathrm{HCO}_{3}{ }^{-}$induced fluid absorption in the absence of luminal $\mathrm{Cl}^{-}$. Two potential explanations come into mind: Either PAT-1 imports the anion $\mathrm{HCO}_{3}{ }^{-}$during $\mathrm{CO}_{2} / \mathrm{HCO}_{3}{ }^{-}$ induced fluid absorption, NHE3 imports the cation $\mathrm{Na}^{+}$, or $\mathrm{Na}^{+}$ absorption via NHE3 is sufficient to mediate $\mathrm{CO}_{2} / \mathrm{HCO}_{3}{ }^{-}$ induced fluid absorption and the absence of PAT-1 interferes with NHE3 expression and/or activity. We measured this but obtained no indication for a downregulation of NHE3 expression, function or an alteration of NHE3 membrane localization in PAT-1 deficient enterocytes.

In contrast, we did find a decrease in acid-activated NHE3 transport rates in DRA-deficient villous enterocytes, and this was accompanied by a significant part of NHE3 being localised to the terminal web region in the DRA KO jejunum (Fig. 8). We speculate that the differential distribution of NHE3 in the microvillar vs. terminal web region, which correlates more or less with NHE3 activity both in rat proximal tubule [36], and in murine ileum $[8,28]$, may be a consequence of the different steady-state $\mathrm{pH}_{\mathrm{i}}$ in the villous enterocytes in the DRA vs. PAT-1 $\mathrm{KO}$ jejunal villous enterocytes (Figs. 7 and 8). To test this hypothesis, we also studied NHE3 localization in CFTR KO villous enterocytes, which also have an increased $\mathrm{pH}_{\mathrm{i}}$ compared 
to WT both in the measurements done by Simpson et al. [40] and by us, and indeed, found more NHE3 in the terminal web zone in CFTR KO compared to WT enterocytes (data not shown). Thus a decrease in NHE3 transport, secondary to DRA deletion, may in part explain the reduced $\mathrm{CO}_{2} / \mathrm{HCO}_{3}{ }^{-}-$ stimulated fluid absorptive rates in DRA KO jejunum but it cannot be the explanation for the reduction in $\mathrm{CO}_{2} / \mathrm{HCO}_{3}{ }^{-}$ induced fluid absorptive rate in PAT-1 KO jejunum. Therefore, we hypothetise that PAT-1 imports $\mathrm{HCO}_{3}{ }^{-}$during $\mathrm{CO}_{2} / \mathrm{HCO}_{3}{ }^{-}$induced fluid absorption.

Consistent with our conclusions of $\mathrm{HCO}_{3}{ }^{-}$import via PAT-1 and $\mathrm{HCO}_{3}{ }^{-}$export via DRA was the fact that the genetic deletion of CA2, which is the major intracellular carbonic anhydrase in duodenal epithelial cell [1, 34] and likely in the jejunum as well, resulted in changes in fluid absorption that resembled those seen in DRAdeficient jejunum, but not in PAT-1 deficient jejunum (Figs. 2 and 4). This would be expected, as CA2 would not be necessary for PAT-1-mediated $\mathrm{HCO}_{3}{ }^{-}$import from the jejunal lumen.

Simpson et al. [42] were the first to suggest $\mathrm{HCO}_{3}{ }^{-}$import by PAT-1 into villous enterocytes during cellular acidification in isolated murine duodenal mucosa. In that paper, the authors measured the GlySar (a nonhydrolysable dipeptide)-induced

\section{Luminal Saline Perfusion $\mathrm{pH}_{\text {in }}$ 7.4, $\mathrm{pH}_{\text {out }} 6.9$}

duodenocyte $\mathrm{pH}_{\mathrm{i}}$ change and calculated the presumed $\mathrm{Cl}^{-} /$ $\mathrm{HCO}_{3}{ }^{-}$exchange rate. Based on the assumption of a depolarised membrane potential of $-25 \mathrm{mV}$ during electrogenic $\mathrm{H}^{+}$-dipeptide absorption, they calculated the driving forces for $\mathrm{HCO}_{3}{ }_{\text {in }}^{-} / \mathrm{Cl}^{-}$out and concluded that $\mathrm{HCO}_{3}{ }^{-}$ uptake in exchange for $\mathrm{Cl}^{-}$via PAT-1 would be possible both if PAT-1 were electroneutral and also if it were electrogenic.

We therefore measured the $\mathrm{pH}_{\mathrm{i}}$ and the surface $\mathrm{pH}$, which is the $\mathrm{pH}$ directly external to the epithelial cells, in the villous epithelium. For $\mathrm{pH}_{\mathrm{i}}$ measurements, we used two techniques: videoimaging of microdissected BCECF-loaded villi and twophoton microscopy in SNARF-loaded villi in exteriorised vascularly perfused jejunum in vivo. Using both approaches, it became apparent that the switch of the perfusate from saline to $\mathrm{CO}_{2} / \mathrm{HCO}_{3}{ }^{-}$caused a persistent decrease in villous enterocyte $\mathrm{pH}_{\mathrm{i}}$. The surface $\mathrm{pH}$ was measured in vivo only, and the measurements demonstrated a strong increase of the surface $\mathrm{pH}$ after the switch from saline, $\mathrm{pH} 7.4$ to a $5 \% \mathrm{CO}_{2} /$ $24 \mathrm{mM} \mathrm{HCO}_{3}{ }^{-}$-containing saline, $\mathrm{pH}$ 7.4. This resulted in a reversal of the proton gradient across the enterocyte apical membrane, with an inward gradient for protons and an outward gradient for $\mathrm{HCO}_{3}{ }^{-}$during saline perfusion, and an outward gradient for protons and inward gradient for $\mathrm{HCO}_{3}{ }^{-}$ during $\mathrm{CO}_{2} / \mathrm{HCO}_{3}{ }^{-}$-containing saline perfusion.

\section{Luminal $\mathrm{CO}_{2} / \mathrm{HCO}_{3}{ }^{-}$Perfusion $\mathrm{pH}_{\text {in }}$ 7.4, $\mathrm{pH}_{\text {out }} 7.4$}

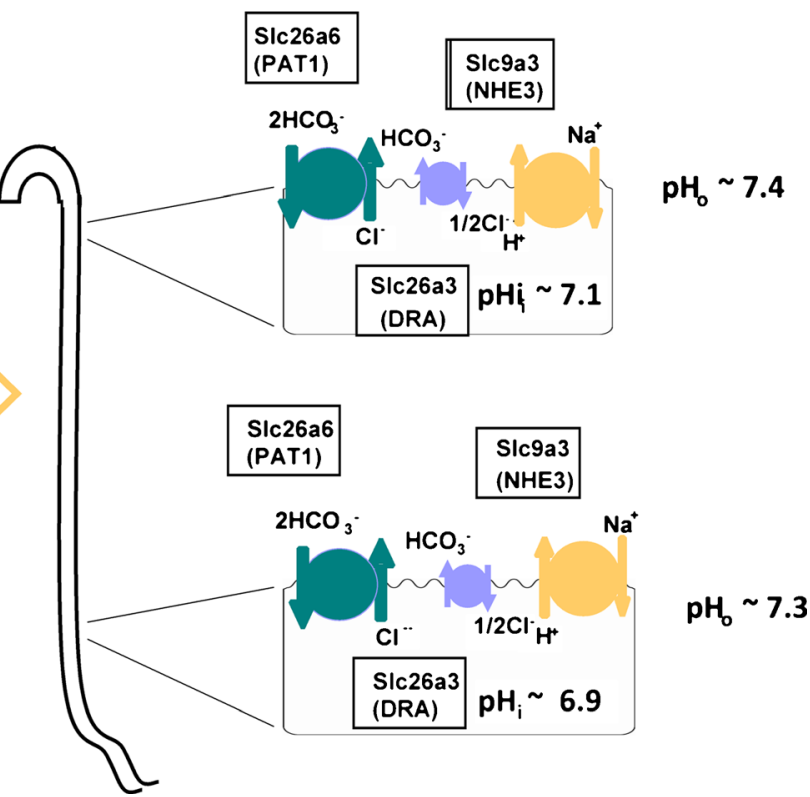

alkalinises the perfusate. The high $\mathrm{pH}_{\mathrm{i}}$ favours DRA-mediated $\mathrm{HCO}_{3}{ }^{-}$ secretion, and it is likely that even PAT-1 will import $\mathrm{Cl}^{-}$in exchange for $\mathrm{HCO}_{3}{ }^{-}$, at least in the acidic extracellular $\mathrm{pH}$ conditions at the base of the villi. The low $\mathrm{pH}_{\mathrm{o}}$ has an inhibitory effect on NHE3. Right panel: after the switch of the perfusate to a $\mathrm{CO}_{2} / \mathrm{HCO}_{3}{ }^{-}$buffer with the same $\mathrm{pH}$, the surface $\mathrm{pH}_{\mathrm{o}}$ is stable at 7.4, while $\mathrm{CO}_{2}$ enters and acidifies the enterocytes. This creates a driving force for PAT-1 mediated $\mathrm{HCO}_{3}{ }^{-}$ absorption; it increases the driving force for NHE3-mediated $\mathrm{Na}^{+}$ absorption, while reducing it for DRA-mediated $\mathrm{HCO}_{3}{ }^{-}$secretion $\mathrm{HCO}_{3}{ }^{-}$absorption via PAT-1. Some $\mathrm{HCO}_{3}{ }^{-}$is likely formed near the enterocyte membrane by extracellular carbonic anhydrases. DRA activity 
Due to the fact that the base of the villi are covered with thick mucus gel and unstirred layer effects likely exist [46], we have to assume that during the luminal perfusion experiments, the rapid flow of solution in the lumen will keep the $\mathrm{pH}$ at the villus tips near the entry of the perfusate similar to that of the inflowing perfusate (i.e., 7.4), while the surface $\mathrm{pH}$ at the base of the villi is likely similar to that measured during the two photon measurements in both the unbuffered and the strongly buffered luminal bath ( $\sim 6.8)$. Given the low surface $\mathrm{pH}$ during saline perfusion at the base of the villi, both DRA and PAT-1 would probably export $\mathrm{HCO}_{3}{ }^{-}$in exchange for $\mathrm{Cl}^{-}$ in this location, no matter what the coupling of the two anions. Because the surface $\mathrm{pH}$ at the tip of the villi is probably markedly more alkaline than in the villous base during saline $\mathrm{pH} 7.4$ perfusion, it is possible that PAT- 1 imports $\mathrm{HCO}_{3}{ }^{-}$at the tip and $\mathrm{Cl}^{-}$at the villous base in the absence of luminal $\mathrm{CO}_{2} / \mathrm{HCO}_{3}{ }^{-}$. Extracellular carbonic anhydrases are expressed in the luminal surface of the enterocytes and would be able to convert $\mathrm{CO}_{2}$, which continuously diffuses from the epithelial cells into the lumen, to $\mathrm{HCO}_{3}{ }^{-}$. This would explain why effluent $\mathrm{pH}$ is less acidic in PAT-1 KO than WT mice during saline perfusion.

After a switch to $5 \% \mathrm{CO}_{2} / \mathrm{HCO}_{3}{ }^{-}$, surface $\mathrm{pH}$ increased everywhere along the villus, and enterocyte $\mathrm{pH}_{\mathrm{i}}$ decreased (Fig. 6). The strong decrease of $\mathrm{pH}_{\mathrm{i}}$ and increase of $\mathrm{pH}_{\mathrm{o}}$ (Fig. 6 and Fig. S3) in comparison with that seen when the exposed jejunum was perfused with a strongly Hepes/Tris buffer, is likely due to the fact that $\mathrm{CO}_{2}$ entry into the enterocytes at the base may stimulate $\mathrm{HCO}_{3}{ }^{-}$secretion [19, 31]. This resulted in a driving force for $\mathrm{HCO}_{3}{ }^{-}$uptake into the cell. Although calibration of $\mathrm{pH}_{\mathrm{i}}$ is fraught with some uncertainties in vivo, the $\mathrm{pH}_{\mathrm{i}}$ experiments in microdissected villi confirm the fact that $\mathrm{pH}_{\mathrm{i}}$ decreases to values of at least 7.0 if not lower immediately after the switch from Hepes $/ \mathrm{O}_{2}$ to $\mathrm{CO}_{2} / \mathrm{HCO}_{3}{ }^{-}$, which would create an inwardly $\mathrm{HCO}_{3}{ }^{-}$ gradient of at least twofold. In the case of a $2 \mathrm{HCO}_{3}^{-}: 1 \mathrm{Cl}^{-}$ stochiometry for PAT-1 and a $2 \mathrm{Cl}^{-}: 1 \mathrm{HCO}_{3}{ }^{-}$stochiometry for DRA [39], it is likely that PAT-1 imports $\mathrm{HCO}_{3}{ }^{-}$and DRA may or may not be active depending on the degree of intracellular acidification and the extracellular ratio of $\mathrm{HCO}_{3}{ }^{-}$to $\mathrm{Cl}^{-}$concentration. This would be consistent with our data. The assumption that both transporters operate in an electroneutral transport mode but are differentially expressed along the crypt-villus axis, with DRA being expressed at the base of the villi and PAT-1 near the tips [41], is inconsistent with the fact that DRA KO enterocytes in the villus tips, measured in vitro, are more alkaline than WT enterocytes. In addition, it would be difficult to understand why the absence of PAT-1, but not of DRA, abolishes the $\mathrm{Cl}^{-}$-independent part of $\mathrm{CO}_{2} / \mathrm{HCO}_{3}{ }^{-}$-induced fluid absorption. Also, the differential effects of PAT-1 and DRA deletion on enterocyte steady-state $\mathrm{pH}_{\mathrm{i}}$, and the reciprocal $\mathrm{pH}$ change of the effluent during jejunal perfusion, are difficult to reconcile with a 1:1 coupling for both transporters. We attempted to get further insight into a potential electrogenicity of PAT- 1 mediated $\mathrm{HCO}_{3}{ }^{-}$absorption by studying $\mathrm{CO}_{2} / \mathrm{HCO}_{3}{ }^{-}$-stimulated fluid absorption after manipulation of the enterocyte membrane potential by high luminal $\mathrm{K}^{+}$, as used by Simpson et al. in isolated duodenal mucosa [49] or by application of luminal glucose, which will depolarise the apical membrane potential through $\mathrm{Na}^{+}$-coupled glucose absorption. However, we felt that these manoeuvres to depolarise the apical membrane potential in vivo influenced too many other parameters to yield clearly interpretable results. Therefore, our data are consistent with but do not prove a 2:1 coupling ratio for $\mathrm{HCO}_{3}{ }^{-} / \mathrm{Cl}^{-}$for PAT-1, and with both a 2:1 as well as a $1: 1$ coupling of $\mathrm{Cl}^{-}$to $\mathrm{HCO}_{3}{ }^{-}$for DRA. A hypothetical model depicting a summary of our results and our interpretation of them is given in Fig. 9.

In summary, this study suggests a novel physiological function for the Slc26 family member PAT-1 (Slc26a6) as an important transport protein involved in jejunal $\mathrm{Na}^{+} \mathrm{HCO}_{3}{ }^{-}$ absorption and acid/base balance, whereas DRA is predominantly involved with $\mathrm{Cl}^{-}$absorption. This may explain the particularly high expression levels for PAT- 1 in the upper small intestine. The reason for the expression of two anion transporters with $\mathrm{Cl}^{-} / \mathrm{HCO}_{3}{ }^{-}$exchanger activity with similar expression levels and cellular location may lie in the fact that the two operate optimally under different ionic conditions, and thus ensure the absorption of monovalent anions $\left(\mathrm{Cl}^{-}\right.$or $\mathrm{HCO}_{3}{ }^{-}$) over a wide range of luminal $\mathrm{Cl}^{-}$and $\mathrm{HCO}_{3}{ }^{-}$ concentrations. This concept helps explain many clinical observations, i.e., the high loss of $\mathrm{HCO}_{3}^{-}$by patients with a small intestinal stoma, and may change future therapeutic approaches to such problems.

Acknowledgments This work was funded by grants from the Deutsche Forschungsgemeinschaft Se460/13-4 and 9-6 as well as SFB621-C9 (to U.S.), and NIH grant DK 62809 (to M.S.). We thank Brigitte Rausch for genotyping, Mingmin Chen for help with the steady-state $\mathrm{pH}_{\mathrm{i}}$ measurements, and Andrew Short for suggestions related to grammar, style and clarity.

Conflict of interest The authors have no conflict of interest to disclose.

Open Access This article is distributed under the terms of the Creative Commons Attribution License which permits any use, distribution, and reproduction in any medium, provided the original author(s) and the source are credited.

\section{References}

1. Akiba Y, Ghayouri S, Takeuchi T et al (2006) Carbonic anhydrases and mucosal vanilloid receptors help mediate the hyperemic response to luminal $\mathrm{CO}_{2}$ in rat duodenum. Gastroenterology 131:142-152

2. Alper SL, Stewart AK, Vandorpe DH et al (2011) Native and recombinant Slc26a3 (downregulated in adenoma, Dra) do not 
exhibit properties of $2 \mathrm{Cl}^{-} / 1 \mathrm{HCO}_{3}{ }^{-}$exchange. Am J Physiol Cell Physiol 300:C276-286

3. Alvarez BV, Vilas GL, Casey JR (2005) Metabolon disruption: a mechanism that regulates bicarbonate transport. The EMBO journal 24:2499-2511

4. Atuma C, Strugala V, Allen A, Holm L (2001) The adherent gastrointestinal mucus gel layer: thickness and physical state in vivo. Am J Physiol Gastrointest Liver Physiol 280:G922-929

5. Bookstein C, Xie Y, Rabenau K et al (1997) Tissue distribution of $\mathrm{Na}^{+} / \mathrm{H}^{+}$exchanger isoforms NHE2 and NHE4 in rat intestine and kidney. Am J Physiol 273:C1496-1505

6. Broere N, Chen M, Cinar A et al (2009) Defective jejunal and colonic salt absorption and altered $\mathrm{Na}(+) / \mathrm{H}(+)$ exchanger 3 (NHE3) activity in NHE regulatory factor 1 (NHERF1) adaptor protein-deficient mice. Pflugers Arch 457:1079-1091

7. Chen M, Singh A, Xiao F et al (2010) Gene ablation for PEPT1 in mice abolishes the effects of dipeptides on small intestinal fluid absorption, short-circuit current, and intracellular pH. Am J Physiol Gastrointest Liver Physiol 299:G265-274

8. Chen M, Sultan A, Cinar A et al (2010) Loss of PDZ-adaptor protein NHERF2 affects membrane localization and cGMP- and $\left[\mathrm{Ca}^{2+}\right]$ - but not cAMP-dependent regulation of $\mathrm{Na}+/ \mathrm{H}+$ exchanger 3 in murine intestine. J Physiol 588:5049-5063

9. Chernova MN, Jiang L, Friedman DJ et al (2005) Functional comparison of mouse slc26a6 anion exchanger with human SLC26A6 polypeptide variants: differences in anion selectivity, regulation, and electrogenicity. J Biol Chem 280:8564-8580

10. Chernova MN, Jiang L, Shmukler BE et al (2003) Acute regulation of the SLC26A3 congenital chloride diarrhoea anion exchanger (DRA) expressed in Xenopus oocytes. J Physiol 549:3-19

11. Davis GR, Santa Ana CA, Morawski SG, Fordtran JS (1982) Permeability characteristics of human jejunum, ileum, proximal colon and distal colon: results of potential difference measurements and unidirectional fluxes. Gastroenterology 83:844-850

12. Fordtran JS, Rector FC Jr, Carter NW (1968) The mechanisms of sodium absorption in the human small intestine. J Clin Invest 47:884 900

13. Freel RW, Hatch M, Green M, Soleimani M (2006) Ileal oxalate absorption and urinary oxalate excretion are enhanced in Slc26a6 null mice. Am J Physiol Gastrointest Liver Physiol 290:G719-728

14. Freel RW, Morozumi M, Hatch M (2009) Parsing apical oxalate exchange in Caco-2BBel monolayers: siRNA knockdown of SLC26A6 reveals the role and properties of PAT-1. Am J Physiol Gastrointest Liver Physiol 297:G918-929

15. Freel RW, Whittamore JM, Hatch M (2013) Transcellular oxalate and $\mathrm{Cl}^{-}$absorption in mouse intestine is mediated by the DRA anion exchanger Slc26a3, and DRA deletion decreases urinary oxalate. Am J Physiol Gastrointest Liver Physiol 305:G520-G527

16. Gawenis LR, Stien X, Shull GE et al (2002) Intestinal NaCl transport in NHE2 and NHE3 knockout mice. Am J Physiol Gastrointest Liver Physiol 282:G776-784

17. Hoogerwerf WA, Tsao SC, Devuyst O et al (1996) NHE2 and NHE3 are human and rabbit intestinal brush-border proteins. Am J Physiol 270:G29-41

18. Hubel KA (1973) Effect of luminal sodium concentration on bicarbonate absorption in rat jejunum. J Clin Invest 52:3172-3179

19. Jakab RL, Collaco AM, Ameen NA (2013) Characterization of CFTR High Expresser cells in the intestine. Am J Physiol Gastrointest Liver Physiol 305(6):G453-465

20. Kato A, Romero MF (2011) Regulation of electroneutral $\mathrm{NaCl}$ absorption by the small intestine. Annu Rev Physiol 73:261-281

21. Knickelbein R, Aronson PS, Atherton W, Dobbins JW (1983) Sodium and chloride transport across rabbit ileal brush border. I. Evidence for Na-H exchange. Am J Physiol 245:G504-510

22. Knickelbein R, Aronson PS, Schron CM, Seifter J, Dobbins JW (1985) Sodium and chloride transport across rabbit ileal brush border:
II. Evidence for $\mathrm{Cl}^{-} \mathrm{HCO}_{3}$ exchange and mechanism of coupling. Am J Physiol 249:G236-245

23. Knickelbein RG, Aronson PS, Dobbins JW (1988) Membrane distribution of sodium-hydrogen and chloride-bicarbonate exchangers in crypt and villus cell membranes from rabbit ileum. J Clin Invest 82:2158-2163

24. Knickelbein RG, Aronson PS, Dobbins JW (1990) Characterization of $\mathrm{Na}(+)-\mathrm{H}^{+}$exchangers on villus cells in rabbit ileum. Am J Physiol 259:G802-806

25. Lamprecht G, Baisch S, Schoenleber E, Gregor M (2005) Transport properties of the human intestinal anion exchanger DRA (downregulated in adenoma) in transfected HEK293 cells. Pflugers Arch 449:479-490

26. Lamprecht G, Schaefer J, Dietz K, Gregor M (2006) Chloride and bicarbonate have similar affinities to the intestinal anion exchanger DRA (down regulated in adenoma). Pflugers Arch 452:307-315

27. Lien YH, Lai LW (1998) Respiratory acidosis in carbonic anhydrase II-deficient mice. Am J Physiol 274:L301-304

28. Lin S, Yeruva S, He P et al (2010) Lysophosphatidic acid stimulates the intestinal brush border $\mathrm{Na}(+) / \mathrm{H}(+)$ exchanger 3 and fluid absorption via LPA(5) and NHERF2. Gastroenterology 138:649-658

29. Maxwell JD, Watson WC, Watt JK, Ferguson A (1968) Radiotelemetering studies of jejunal $\mathrm{pH}$ before and after vagotomy and pyloroplasty. Gut 9:612-616

30. Melvin JE, Park K, Richardson L, Schultheis PJ, Shull GE (1999) Mouse down-regulated in adenoma (DRA) is an intestinal $\mathrm{Cl}(-)$ $\mathrm{HCO}(3)(-)$ exchanger and is up-regulated in colon of mice lacking the NHE3 $\mathrm{Na}(+) / \mathrm{H}(+)$ exchanger. J Biol Chem 274:22855-22861

31. Mizumori M, Meyerowitz J, Takeuchi T et al (2006) Epithelial carbonic anhydrases facilitate $\mathrm{PCO}_{2}$ and $\mathrm{pH}$ regulation in rat duodenal mucosa. J Physiol 573:827-842

32. Nader M, Lamprecht G, Classen M, Seidler U (1994) Different regulation by $\mathrm{pH}_{\mathrm{i}}$ and osmolarity of the rabbit ileum brush-border and parietal cell basolateral anion exchanger. J Physiol 481(Pt 3): 605-615

33. Ovesen L, Bendtsen F, Tage-Jensen U et al (1986) Intraluminal $\mathrm{pH}$ in the stomach, duodenum, and proximal jejunum in normal subjects and patients with exocrine pancreatic insufficiency. Gastroenterology 90:958-962

34. Parkkila S, Parkkila AK, Juvonen T, Rajaniemi H (1994) Distribution of the carbonic anhydrase isoenzymes I, II, and VI in the human alimentary tract. Gut 35:646-650

35. Podesta RB, Mettrick DF (1977) $\mathrm{HCO}_{3}$ transport in rat jejunum: relationship to $\mathrm{NaCl}$ and $\mathrm{H} 2 \mathrm{O}$ transport in vivo. Am J Physiol 232: E62-68

36. Riquier AD, Lee DH, McDonough AA (2009) Renal NHE3 and $\mathrm{NaPi} 2$ partition into distinct membrane domains. Am J Physiol Cell Physiol 296:C900-910

37. Schedl HP, Clifton JA (1963) Solute and water absorption by the human small intestine. Nature 199:1264-1267

38. Seidler U, Rottinghaus I, Hillesheim J et al (2008) Sodium and chloride absorptive defects in the small intestine in Slc26a6 null mice. Pflugers Arch 455:757-766

39. Shcheynikov N, Wang Y, Park M et al (2006) Coupling modes and stoichiometry of $\mathrm{Cl}^{-} / \mathrm{HCO}_{3}{ }^{-}$exchange by slc26a3 and slc26a6. J Gen Physiol 127:511-524

40. Simpson JE, Gawenis LR, Walker NM, Boyle KT, Clarke LL (2005) Chloride conductance of CFTR facilitates basal $\mathrm{Cl}^{-} / \mathrm{HCO}_{3}{ }^{-}$ exchange in the villous epithelium of intact murine duodenum. Am J Physiol Gastrointest Liver Physiol 288:G1241-1251

41. Simpson JE, Schweinfest CW, Shull GE et al (2007) PAT-1 (Slc26a6) is the predominant apical membrane $\mathrm{Cl}^{-} / \mathrm{HCO}_{3}{ }^{-}$exchanger in the upper villous epithelium of the murine duodenum. Am J Physiol Gastrointest Liver Physiol 292:G1079-1088 
42. Simpson JE, Walker NM, Supuran CT, Soleimani M, Clarke LL (2010) Putative anion transporter-1 (Pat-1, Slc26a6) contributes to intracellular $\mathrm{pH}$ regulation during $\mathrm{H}^{+}$-dipeptide transport in duodenal villous epithelium. Am J Physiol Gastrointest Liver Physiol 298:G683-691

43. Singh AK, Liu Y, Riederer B et al. (2013) Molecular transport machinery involved in orchestrating luminal acid-induced duodenal bicarbonate secretion in vivo. J Physiol. doi:10.1113/jphysiol.2013. 254854

44. Singh AK, Riederer B, Chen M et al (2010) The switch of intestinal Slc26 exchangers from anion absorptive to $\mathrm{HCO}_{3}{ }^{-}$secretory mode is dependent on CFTR anion channel function. Am J Physiol Cell Physiol 298:C1057-1065

45. Singh AK, Xia W, Riederer B et al (2013) Essential role of the electroneutral $\mathrm{Na}^{+}-\mathrm{HCO}_{3}{ }^{-}$cotransporter $\mathrm{NBCn} 1$ in murine duodenal acid-base balance and colonic mucus layer build-up in vivo. J Physiol 591:2189-2204

46. Sjoblom M, Singh AK, Zheng W et al (2009) Duodenal acidity "sensing" but not epithelial $\mathrm{HCO}_{3}{ }^{-}$supply is critically dependent on carbonic anhydrase II expression. Proc Natl Acad Sci U S A 106: 13094-13099

47. Turnberg LA, Bieberdorf FA, Morawski SG, Fordtran JS (1970) Interrelationships of chloride, bicarbonate, sodium, and hydrogen transport in the human ileum. J Clin Invest 49:557-567

48. Turnberg LA, Fordtran JS, Rector FC (1969) Bicarbonate absorption in the human jejunum. Gut 10:415
49. Walker NM, Simpson JE, Hoover EE et al (2011) Functional activity of Pat-1 (Slc26a6) $\mathrm{Cl}(-) / \mathrm{HCO}(3)(-)$ exchange in the lower villus epithelium of murine duodenum. Acta Physiol (Oxf) 201:21-31

50. Walker NM, Simpson JE, Yen PF et al (2008) Down-regulated in adenoma $\mathrm{Cl} / \mathrm{HCO} 3$ exchanger couples with $\mathrm{Na} / \mathrm{H}$ exchanger 3 for $\mathrm{NaCl}$ absorption in murine small intestine. Gastroenterology 135(1645-1653):e1643

51. Wang Z, Petrovic S, Mann E, Soleimani M (2002) Identification of an apical $\mathrm{Cl}(-) / \mathrm{HCO} 3(-)$ exchanger in the small intestine. Am J Physiol Gastrointest Liver Physiol 282:G573-579

52. Worcester EM (2002) Stones from bowel disease. Endocrinology and metabolism clinics of North America 31:979-999

53. Xiao F, Juric M, Li J et al (2011) Loss of downregulated in adenoma (DRA) impairs mucosal $\mathrm{HCO}_{3}{ }^{-}$secretion in murine ileocolonic inflammation. Inflamm Bowel Dis 18:101-111

\section{Author contributions}

W.X., Q.Y., B.R., A.K.S., R.E., and U.S. designed, performed and analysed experiments, S.Y., P.S., D.A.T., and M.S. provided expert assistance and suggestions, and U.S. wrote the manuscript. 